\title{
O Índice de Condições de Vida (ICV) em Territórios Rurais do Nordeste: evidências para os territórios Açu-Mossoró e Sertão do Apodi, no Rio Grande do Norte ${ }^{1}$
}

\author{
The Living Conditions Index (LCI) in Rural Territories of the Brazilian \\ Northeastern region: evidence for the Açu-Mossoró and Sertão do Apodi \\ territories, in Rio Grande do Norte state
}

Emanoel Márcio Nunes ${ }^{1}$ (D), Paulo Sidney Gomes da Silva ${ }^{2}$ (D), Márcia Regina Farias da Silva ${ }^{1}$ (i), Vinícius Claudino de Sá1

${ }^{1}$ Universidade do Estado do Rio Grande do Norte (UERN), Mossoró (RN), Brasil. E-mail: emanoelnunes@uern.br mreginafarias@hotmail.com; viniciusclaudino@gmail.com

2Instituto Federal de Educação, Ciência e Tecnologia do Rio Grande do Norte (IFRN), Campus Ipanguaçu (RN), Brasil. Email: paulo.sidney11@gmail.com

Como citar: Nunes, E.M., Silva, P. S. G., Silva, M. R. F., Sá, V. C. (2020). O Índice de Condições de Vida (ICV) em Territórios Rurais do Nordeste: evidências para os territórios Açu-Mossoró e Sertão do Apodi, no Rio Grande do Norte. Revista de Economia e Sociologia Rural, 58(1), e190917. https://doi.org/10.1590/1806-9479.2020.190917

Resumo: O objetivo deste artigo é apresentar a importância do Índice de Condições de Vida (ICV) como um indicador que possibilita a representação das mudanças percebidas no e pelo público-alvo das ações que vêm sendo implementadas desde 2003 nos territórios Açu-Mossoró e Sertão do Apodi, no Rio Grande do Norte. A metodologia foi a desenvolvida pela Secretaria de Desenvolvimento Territorial (SDT) do Ministério do Desenvolvimento Agrário (MDA) e consiste na definição dos ICVs, em que o foco central está em captar a percepção que os indivíduos têm sobre suas condições de vida. Os resultados indicam que não há correspondência direta entre fatores, características e efeitos do desenvolvimento no sentido de que a existência de ativos e capitais aliados às liberdades individuais se traduz em mudanças significativas nas condições de vida, embora a percepção sobre as condições de vida seja algo que varia substancialmente entre indivíduos ou famílias.

Palavras-chaves: ICV, políticas públicas, desenvolvimento territorial.

\begin{abstract}
The objective of this article is to present the importance of the Index of Living Conditions (ILC) as an indicator that allows the representation of the changes perceived in and by the target public of the actions that, since 2003, have been settled in Açu-Mossoró and Sertão do Apodi, in Rio Grande do Norte. As a methodological process, it was developed by the Department of Territorial Development (SDT) of the Brazilian Ministry of Agrarian Development (MDA) and consists of the definition of LCls, where the central focus is capturing individuals' perceptions about their living conditions. The results indicate that there is no direct correspondence between factors, characteristics and effects of development in the sense that the existence of assets and capitals along with individual liberties translates into significant changes in living conditions, although the perception about living conditions is something that varies substantially between individuals or families.
\end{abstract}

Keywords: ICV, public policies, territorial development.

\footnotetext{
${ }^{1}$ Este trabalho é resultado de pesquisas desenvolvidas no âmbito da agricultura familiar, e contou com auxílio financeiro do MDA/SDT/CNPq através do Edital 005/2009 - Gestão de Territórios Rurais.
} 


\section{Introdução}

O meio rural de regiões pouco desenvolvidas apresenta como característica uma precária infraestrutura das suas unidades de produção e pouca escolaridade, o que reproduz um ambiente de fragilidade marcado por baixos rendimentos da sua agricultura, ausência de organização coletiva, reduzido acesso a bens, baixo nível tecnológico, entre outros fatores que limitam o processo de desenvolvimento. Durante décadas, o "desenvolvimento" vem sendo discutido e os seus significados destacaram mais o aspecto econômico, como prosperidade, riqueza, progresso, crescimento, industrialização, propagação etc. Por outro lado, mais recentemente por volta dos anos 1990 e 2000, os significados passaram a ter outra conotação, sendo relacionados a aspectos mais sociais, a exemplo dos apelos por melhoria das condições de vida, distribuição e maior acesso à riqueza, inclusão produtiva, redução de desigualdades, sustentabilidade, autonomia, entre outros. Na verdade, o debate mais recente tem realizado esforços no sentido de melhor interpretar e explicar como indivíduos e suas organizações coletivas engendram processos que lhes são comuns e expressam suas concepções a respeito dos fatores, das características e dos efeitos do desenvolvimento. Esse segundo momento resulta do enfraquecimento da ortodoxia keynesiana, que influenciou fortemente no primeiro período com ênfase na intervenção do Estado nas economias nacionais, mas que foi perdendo espaço, no segundo momento, para um discurso neoliberal e sua defesa pelo Estado mínimo. Isso levou ao enfraquecimento das economias nacionais e a sucessivas crises que afetaram ainda mais as regiões pouco desenvolvidas, aprofundando a desigualdade e a exclusão.

É considerando esse segundo momento que é definido o propósito de construir um índice de desenvolvimento territorial, ou Índice de Condições de Vida (ICV), a partir da percepção dos indivíduos de territórios (agricultores familiares e suas unidades de produção), acerca do desenvolvimento por meio de múltiplos níveis e dimensões. Este empenho tem sido principalmente devido às críticas quanto à insuficiência das análises unidimensionais, aquelas em que o desenvolvimento, seja numa escala mais ampla ou simplesmente representativo de um recorte espacial, seria obtido a partir de aspectos e fatores meramente econômicos e por incrementos na repartição da riqueza material, especialmente do Produto Interno Bruto (PIB) per capita. Da mesma forma, cabe ressaltar toda a preocupação acumulada em décadas em termos de avanços teóricos e metodológicos na constituição de novas perspectivas de análise, novas escalas ou recortes e suas contribuições, num esforço significativo de superação do recorte setorial e dos não mais adequados limites espaciais/regionais para propor ações no sentido de promover e dar significados ao desenvolvimento, e de preferência a partir dos fatores e aspectos mais recentes.

Ao questionar os significados do desenvolvimento, tanto os do primeiro momento, com ênfase nos aspectos meramente econômicos e de recorte espacial e setorial, como os do segundo momento, baseados em aspectos mais sociais e várias dimensões, assim como de tentativa de constituir recorte territorial e multissetorial, a pergunta principal deste artigo é: qual a validade, segundo questionamento em que está ancorada a obra de Sen (2000), de uma concepção de desenvolvimento arquitetada a partir de aspectos meramente econômicos, que não se reflete nas condições de vida das populações rurais de regiões pouco desenvolvidas? E a aplicação do Índice de Condições de Vida (ICV) demonstra que esta metodologia possibilita captar a diversidade de situações em determinado momento, as quais podem ser comparadas com um momento posterior, a partir do qual torna-se possível explicar a complexidade e a diversidade de realidades territoriais? Na tentativa de responder a essas questões, o artigo descarta os significados que sugerem a configuração do primeiro momento, e busca ressaltar, captando a percepção dos atores territoriais (agricultores familiares), os significados que sugerem como alternativas a configuração do segundo momento, ou seja, os que enfatizam a garantia de direitos e outras dimensões da vida humana.

Diante disso, o presente artigo tem como objetivo apresentar a importância do Índice de Condições de Vida (ICV) como um indicador que possibilita a representação das mudanças por meio da percepção pelo público-alvo das ações que vêm sendo implantadas desde o ano de 2003, de forma específica nos territórios Açu-Mossoró e Sertão do Apodi, no Rio Grande 
do Norte. O ICV é um indicador sintético de desenvolvimento territorial que permite apreender por meio de dimensões (econômica, social, demográfico-ambiental e políticoinstitucional), a percepção que os indivíduos têm sobre suas condições de vida. Esta proposta foi elaborada e amplamente incorporada pela Secretaria de Desenvolvimento Territorial (SDT), vinculada ao Ministério do Desenvolvimento Agrário (MDA), e está fundamentada na perspectiva das capacitações de Amartya Sen.

O ICV vem sendo difundido desde 2009 em centenas de Territórios Rurais brasileiros, desenvolvida numa parceria com várias universidades nacionais e com o Conselho Nacional de Desenvolvimento Científico e Tecnológico (CNPq), em edital para Gestão dos Territórios Rurais. Os resultados desses estudos já estão sendo apresentados, conforme foi possível verificar em Rambo et al. (2012), que mostram trabalhos sobre o ICV no território Zona Sul, no Rio Grande do Sul; Rambo et al. (2015), que apresentam metodologias e avaliações de dinâmicas territoriais do desenvolvimento rural; e Casimiro et al. (2015), que avaliaram a qualidade de vida do território Reforma, em Mato Grosso do Sul, por meio do ICV, tendo como foco (i) a análise do perfil familiar dos agricultores familiares, fonte de renda, nível educacional e a análise da participação em associações dos agricultores familiares.

Já Bastian et al. (2016) apresentam o ICV como uma metodologia de análise e avaliação do desenvolvimento territorial que pode contribuir para a busca de novas referências para os estudos dos processos sociais em espaços rurais; e, por fim, Caniello (2016) avaliou as condições de vida da população rural no Brasil, por meio da análise do ICV apurados em uma mostra de 37 territórios da cidadania; e mais recentemente, Toigo \& Conterato (2017), que estudaram a construção do Índice de Condição de Vida (ICV), baseado na Abordagem das Capacitações e dos Meios de Vida, e sua aplicação no Território Rural Zona Sul do Rio Grande do Sul. Dessa forma, os estudos supracitados são de suma importância para realização da análise e discussão dos resultados da pesquisa realizada nos territórios Açu-Mossoró e Sertão do Apodi, no Rio Grande do Norte, em relação às outras regiões do Brasil.

\section{Referencial teórico}

\subsection{O desenvolvimento como liberdade: breves considerações}

Ao analisar o desenvolvimento e os seus significados, especialmente os do segundo momento, o economista indiano Amartya Sen, Prêmio Nobel em Economia de 1998, contribuiu imensamente para estabelecer uma nova compreensão acerca de conceitos tais como miséria, pobreza, fome e bem-estar social. Em sua obra, Desenvolvimento como Liberdade, Sen (2000) procura analisar, sob um viés recente e diferenciado, o papel e os significados do desenvolvimento em contraposição ao viés restritivo que o associa a aspectos meramente econômicos, a exemplo dos grandes agregados macroeconômicos (Produto, Renda e Emprego) e suas derivações, ou seja, o progresso tecnológico, a industrialização, a modernização social etc. Embora tais fatores contribuam diretamente para a expansão de liberdades que possam ser usufruídas pelos membros de uma determinada sociedade, para Sen (2000), o crescimento econômico não pode ser considerado um fim em si mesmo, de modo que o desenvolvimento tem que estar relacionado sobretudo com a melhoria das condições de vida dos indivíduos e com o fortalecimento de suas liberdades.

O desenvolvimento, segundo Sen (2000), não pode ser analisado apenas sob o viés meramente econômico, ou seja, dos grandes agregados macroeconômicos Produto, Renda e Emprego e, para demonstrar isso, são lançados exemplos que questionam a eficácia de uma análise realizada apenas baseada neste viés, ao mesmo tempo em que ilustram a teoria do desenvolvimento como liberdade. Para Sen (2000), "o que as pessoas conseguem realizar é influenciado pelo surgimento de oportunidades econômicas, de liberdades políticas, de poderes sociais e por condições habilitadoras de aprendizado, como boa saúde, educação básica e incentivo e aperfeiçoamento de iniciativas" (Sen, 2010, p. 18).

A liberdade oriunda destas disposições institucionais é, segundo Sen (2000), influenciada pelas próprias ações livres dos agentes, como uma via de mão dupla, "mediante a liberdade de participar da tomada de decisões, sejam públicas ou privadas, que fazem lançar o 
progresso dessas oportunidades" (Sen, 2010, p. 18), podendo ampliar ainda mais a sua própria liberdade. Dessa forma, as liberdades constitutivas, como a liberdade de participação política, de receber educação básica e assistência médica, não apenas contribuem para o círculo virtuoso do desenvolvimento, mas também são fundamentais para a consolidação e expansão das próprias liberdades constitutivas. De maneira inversa, a limitação de uma liberdade específica, tal como uma privação de liberdade econômica, no nível de pobreza extrema, por exemplo, contribui para manter a privação de outras espécies de liberdade, como a social ou a política, tornando esse processo um o círculo vicioso do atraso através de um encadeamento no qual fatores negativos geram influências recíprocas e interligadas.

As liberdades políticas, econômicas, sociais, garantias de transparência e segurança protetora, denominadas como "instrumentais" por Sen (2000), têm a capacidade de se ligarem umas às outras contribuindo para o aumento e consolidação da liberdade humana de modo mais amplo. A análise de Sen (2000) acerca do desenvolvimento atenta-se particularmente para a expansão das "capacidades" das pessoas de levar o tipo de vida que elas valorizam, e isso, segundo o autor, com razão. Essas capacidades podem ser potencializadas e ampliadas pela ação das políticas públicas, mas também, por outro lado, a direção dessas políticas pode ser influenciada pelo uso das capacidades de participação e organização coletiva dos atores.

$\mathrm{Na}$ concepção de desenvolvimento de Sen (2000), um processo que contribui para a redução e a remoção do que limitam as escolhas e oportunidades das pessoas promove o alargamento e a ampliação das liberdades. Sendo assim, as instâncias acima relacionadas se aproximam da abordagem das capabilities (capacitações), que propõe avaliar a capacidade, ou melhor, a liberdade de escolha dos indivíduos, quando da realização de ações ou do alcance de situações consideradas desejáveis. Ao questionar este modelo de avaliação, Sen (2000) demonstra que a expectativa de vida de um homem negro, nascido nos Estados Unidos, é menor do que a de um homem chinês ou costarriquenho, o que leva o autor a uma pergunta que perpassa toda a sua obra: qual é a validade de um modelo de desenvolvimento, baseado na riqueza econômica, que não se reflete nas condições de vida das populações?

$\mathrm{Na}$ tentativa de responder a essa questão, Sen (2000) descarta os modelos e significados que se sustentam no foco meramente econômico de análise, e que sinalizam para o utilitarismo, o libertarismo e o liberalismo de Rawls. Para Sen (2000), todos estes modelos não levam em conta o consequencialismo, a garantia de direitos e outras várias dimensões da vida humana além da econômica. O que ele propõe, então, é um modelo que possibilite aos indivíduos o acesso ao tipo de vida que desejariam ter, relacionando bem-estar e desenvolvimento, em que o “[...] padrão ou a qualidade de vida não se mede pela posse de um conjunto de bens, nem pela qualidade a eles inerente, mas nas capacidades dos indivíduos para utilizar esses bens para obter satisfação ou felicidade" (Kageyama, 2008, p. 54).

Conforme Kageyama (2008), é fundamental na perspectiva do Desenvolvimento como Liberdade de Sen (2000) distinguir o que seria um meio e um fim nos processos de desenvolvimento, como forma de evitar confusões entre crescimento e desenvolvimento. Nessa concepção, segundo Kageyama (2008), a renda, por exemplo, embora necessária, representa um meio e não um fim, em que o bem-estar da sociedade depende de como a renda é utilizada, e não apenas do seu nível se alto, médio ou baixo. Para fazer esta distinção entre meios e fins, Sen (2000) apresenta o modus operandi da sua proposta com base nos conceitos de entitlements (intitulamentos) e functionings (funcionamentos). Segundo Kageyama (2008) e Waquil et al. (2007), os primeiros constituem o conjunto de combinações de bens ou de mercadorias que cada indivíduo pode ou está capacitado para possuir. Os intitulamentos são os meios para alcançar certos fins, as condições para realizar escolhas, sendo determinados por arranjos legais, políticos e econômicos. Já os funcionamentos "refletem as várias coisas que uma pessoa pode considerar valioso ter ou fazer" (Sen, 2000, p. 52).

Os funcionamentos, conforme Sen (2000), remetem às realizações, às reais oportunidades de escolha acerca dos estilos de vida possíveis. Com base nessa afirmação Kageyama (2008) corrobora e ressalta que, apesar de serem aspectos importantes da 
existência humana, a abundância material ${ }^{2}$ e a utilidade simplesmente não conseguem dar um significado adequado ao que se define bem-estar humano. Ou seja, além da abundância e da utilidade o indivíduo necessita ter a capacidade de realizar um funcionamento (capability to function). Neste caso, o desenvolvimento é medido pelo conjunto das capacitações dos integrantes de determina população, refletindo a liberdade para levar determinado tipo de vida ou outro, e as capacitações residem nas "combina ações alternativas de funcionamentos cuja realização é factível para o sujeito" (Sen, 2000, p. 57).

Percebe-se, portanto, que a relação existente entre as instâncias apontadas por Kageyama (2008) e a abordagem de Sen (2000) leva a uma compreensão, a saber: a primeira instância, que se refere aos fatores do desenvolvimento, está ligada aos recursos, às condições para a realização das escolhas, ou seja, aos intitulamentos. Já a segunda instância, que se refere às características do desenvolvimento, pode ser relacionada aos elementos de conversão dos meios em fins, dos intitulamentos em capacitações e funcionamentos. Por fim, conforme apontam Waquil et al. (2007), a terceira instância corresponde aos efeitos do desenvolvimento e se baseia em aspectos econômicos e sociais (podendo ainda adicionar dimensões como político-institucional, cultural e demográfico-ambiental), e está relacionada com as capacitações e funcionamentos, mais para as realizações dos indivíduos ou famílias.

A definição do que é necessário para que uma sociedade desfrute de boas condições de vida deverá partir da definição e concepção de bem-estar dos seus próprios integrantes. Assim, como também colocado por van der Ploeg (2008), seriam os próprios indivíduos vistos como agentes ou atores que deveriam, a partir da sua percepção, ou concepção, definir os termos do que as políticas governamentais deveriam buscar efetivar. ${ }^{3} \mathrm{E}$ sua maior contribuição, conforme van der Ploeg (2008), é mostrar que o desenvolvimento está essencialmente ligado às oportunidades que ele cria no sentido de dar condições para que os indivíduos possam fazer escolhas e exercer sua cidadania. E isso inclui não apenas a garantia dos direitos básicos, como saúde e educação, como também segurança, liberdade, habitação e cultura.

\subsection{A perspectiva territorial do desenvolvimento rural e o acompanhamento e avaliação das dinâmicas territoriais}

Pode-se dizer que a perspectiva territorial de desenvolvimento tem representado um avanço no processo de consolidação da democracia, pois se sustenta nos princípios básicos da gestão participativa, da organização coletiva e na valorização da história e da cultura dos atores. Na verdade, busca a integração dos indivíduos ao espaço em que vivem e às instâncias de poder público, para que possam pressionar o Estado por políticas e elaborar estratégias no sentido de solucionar problemas a partir de diálogos e de conflitos. A criação da Secretaria de Desenvolvimento Territorial (SDT), em 2003, pelo Ministério do Desenvolvimento Agrário (MDA) é um exemplo de como o Estado brasileiro vem sinalizando o interesse em superar o recorte setorial que caracteriza as políticas públicas.

No âmbito da SDT/MDA, conforme Leite \& Wesz Júnior (2012) e Nunes et al. (2015), foi criado o Programa de Desenvolvimento Sustentável de Territórios Rurais (Pronat) ${ }^{4}$, em 2003, com a criação no mesmo ano dos Territórios de Identidade, seguido do Programa Territórios

\footnotetext{
2 Conforme Sen (2000), "vivemos um mundo de opulência sem precedentes, mas também de privação e opressão extraordinárias. O desenvolvimento consiste na eliminação de privações de liberdade que limitam as escolhas e as oportunidades das pessoas de exercer ponderadamente sua condição de cidadão."

${ }^{3} \mathrm{E}$ essa representa a base teórica-metodológica em que se acredita que agregar a abordagem das representações sociais a instrumentos como o Índice de condições de Vida (ICV) auxilia na compreensão das dinâmicas territoriais de desenvolvimento rural. Ao compreender, por exemplo, como os atores territoriais interpretam o real, é possível entender como e por que estes se comportam e agem de determinada forma. Considera-se que, compreender as representações sociais é fundamental para a implantação de políticas de desenvolvimento rural.

${ }^{4} \mathrm{O}$ objetivo geral do Pronat consiste em promover iniciativas das institucionalidades representativas dos territórios rurais que objetivem o incremento sustentável nos níveis de qualidade de vida da população rural e está baseado em quatro pontos: (1) fortalecimento das redes sociais de cooperação dos territórios rurais; (2) planejamento e o fortalecimento da gestão social dos territórios; (3) iniciativas territoriais que contribuam para a dinamização e diversificação das economias territoriais e (4) articulação de políticas públicas, com vistas à redução das desigualdades sociais e regionais e a geração de riquezas com equidade social (Brasil, 2004).
} 
da Cidadania (PTC), em 2008. No documento Referências para o Desenvolvimento Territorial Sustentável, a SDT aponta como justificativa para a perspectiva territorial do desenvolvimento rural a constatação de que

[...] as políticas públicas no âmbito da agricultura familiar nas últimas décadas foram insuficientes, ou não foram capazes de possibilitar melhorias nas condições de vida, nem de criar oportunidades inclusivas e prosperidade para as populações que habitam o interior brasileiro. (Brasil, 2003, p. 9)

De acordo com Echeverri (2010), na perspectiva do Pronat o território rural seria o ambiente onde os critérios multidimensionais e o recorte multissetorial que os caracterizam, bem como os elementos mais marcantes que facilitam a coesão social, cultural e territorial, apresentam a predominância de elementos rurais. Nestes territórios, segundo Echeverri (2010), incluem-se espaços urbanizados que compreendem pequenas e médias cidades, vilas e povoados. A esta perspectiva está a ideia de territórios de identidade, em que a identidade está baseada em alguma especificidade, seja cultural, econômica ou ambiental. Para os territórios rurais para ações do Pronat, como consta em Rambo et al. (2012) e Nunes et al. (2019), a seleção teve por base as microrregiões menos favorecidas e que apresentavam densidade demográfica menor que $80 \mathrm{hab} / \mathrm{km}^{2}$ e população média por município de até 50.000 habitantes, bem como a presença de agricultores familiares, famílias assentadas e famílias acampadas (Brasil, 2003).

O funcionamento dos territórios acontece com base no princípio da ação coletiva que influencia e define a sua estrutura organizacional, a qual é sustentada pelo Colegiado de Desenvolvimento Territorial (Codeter). O Colegiado Territorial, conforme Nunes et al. (2015), é um arranjo institucional e instância máxima, por meio do qual se constroem acordos através da discussão, elaboração, deliberação e implantação de projetos constantes no Plano Territorial de Desenvolvimento Territorial Sustentável (PTDRS), catalisando habilidades e competências num conjunto de organizações e agentes, públicos e privados, individuais e coletivos, e operar esses atributos colocando-os a serviço do território (Brasil, 2005).

Conforme consta em Rambo et al. (2012), com base nestes critérios existiam, por volta de 2010, 242 territórios identificados no País, sendo 164 apoiados pelo Pronat, destes, 93 aprovaram seus planos e outros 71 se encontravam em processo de elaboração e qualificação. Em decorrência do Pronat surge, em 2008, o Programa Territórios da Cidadania (PTC), o qual, conforme Rambo et al. (2012), resulta da constatação de desigualdades socioeconômicas agudas entre famílias de agricultores dos próprios territórios. Acerca do financiamento da política territorial, Wesz Júnior \& Leite (2010) resgatam a trajetória e trazem importantes considerações acerca do PTC. Esses autores ressaltam que o que levou à criação dos Territórios da Cidadania foi, conforme Rambo et al. (2012), a constatação de que o Pronat reproduzia o foco em fatores meramente econômicos e no recorte setorial, não conseguindo modificar a estrutura de produção econômica das regiões mais estagnadas, a exemplo da região Nordeste, pois as demandas destas, que Sen (2000) define como "disposições sociais e econômicas" (saúde, educação, saneamento, habitação, direitos civis etc.), se mostram acima da capacidade dos instrumentos do MDA. No PTC, de acordo com Rambo et al. (2012), a ênfase ressalta o combate à pobreza e a conquista de cidadania, sendo este o foco central dos Territórios da Cidadania a partir de 2008, que consiste em tentar superar a pobreza e gerar oportunidades no meio rural através da política de desenvolvimento territorial.

A partir do conceito de território do Pronat, conforme Leite \& Wesz Júnior (2012), o PTC acrescenta novos critérios para os Territórios de Cidadania, prevendo a implantação dos já incorporados no Pronat, com presença de um território por estado em 2008 e dois em 2009. Os critérios de seleção, conforme Rambo et al. (2012), foram: (1) menor Índice do Desenvolvimento Humano (IDH); (2) maior concentração de agricultores familiares e assentados da Reforma Agrária; (3) maior concentração de quilombolas e indígenas; (4) maior número de beneficiários de programas federais de transferência de renda; (5) maior número 
de municípios com baixo dinamismo econômico;(6) maior organização social; (7) menor Índice de Desenvolvimento da Educação Básica (Ideb). O PTC iniciou em 2008 com a indicação de 60 territórios passando, posteriormente, para 120 territórios da cidadania no País.

Diante da complexidade do Programa Territórios da Cidadania (PTC), e sentindo a necessidade de um maior acompanhamento das dinâmicas dos territórios apoiados pelo Pronat, a Secretaria de Desenvolvimento Territorial (SDT/MDA) articulou-se com 27 universidades brasileiras e 37 territórios para a montagem de um importante banco de dados denominado Sistema de Gestão Estratégica (SGE). Conforme Rambo et al. (2012), a finalidade da articulação institucional e operacional com as universidades se baseou no monitoramento e avaliação, por meio de Células de Acompanhamento e Informação (CAls), das políticas implantadas nos territórios. Para Nunes et al. (2014), a estratégia foi a de alimentar o SGE com informações sistematizadas da pesquisa científica, visando orientar o Codeter na implantação dos projetos de desenvolvimento territorial. Buscou-se, ainda, a execução de atividades convergentes para o esforço do desenvolvimento de capacidades humanas e organizacionais e o aperfeiçoamento da gestão social e dos investimentos públicos. Na perspectiva de monitorar, avaliar e disponibilizar para os Codeter's informações dos territórios, sistematizadas pelas Células de Acompanhamento e Informação (CAIs), entre outras ações, o Índice de Condições de Vida (ICV) representou, de um conjunto de pesquisas, um dos principais mecanismos do desenvolvimento na escala humana de territórios rurais.

\section{Metodologia}

\section{1. Área de pesquisa}

Os dois territórios constituíram o ambiente de estudo onde, de acordo com o Brasil (2010), o Território Açu-Mossoró abrange área de $7.974 \mathrm{~km}^{2}$, composto por 14 municípios: Alto do Rodrigues, Areia Branca, Assú, Baraúna, Carnaubais, Grossos, Ipanguaçu, Itajá, Mossoró, Pendências, Porto do Mangue, São Rafael, Serra do Mel e Tibau. Já o Território Sertão do Apodi abrange área de $8.280,20 \mathrm{~km}^{2}$, composto por 17 municípios: Apodi, Campo Grande, Itaú, Janduís, Rodolfo Fernandes, Umarizal, Caraúbas, Felipe Guerra, Governador Dix-Sept Rosado, Messias Targino, Olho-d'água do Borges, Paraú, Patu, Rafael Godeiro, Severiano Melo, Triunfo Potiguar e Upanema.

O primeiro passo metodológico da pesquisa consistiu no cálculo do Índice de Condição de Vida (ICV), baseado nos pontos de geoprocessamento disponibilizados no Sistema de Gestão Estratégia (SGE) pela equipe da Secretaria de Desenvolvimento Territorial (SDT) das comunidades a serem pesquisadas, e foram realizadas visitas exploratórias e de reconhecimento onde seriam desenvolvidas as pesquisas sobre o ICV nos dois territórios. Os municípios (e comunidades) do Território Sertão do Apodi foram: Apodi (Melancias), Caraúbas (Livramento, Poço da Baixa, Iguarapé, Cachoeira I e II), Felipe Guerra (São Lourenço I), Itaú (P.A Boi Selado, P.A Maracaju), Severiano Melo (Associação Ipueira, Associação Pau de Leite), Upanema (Associação Esperança, P.A Nova Vida), Campo Grande (Bom Jesus), Triunfo Potiguar (São Paulo, Poço Redondo, Angicos, Peixoto, Vaca Morta, Futuro, São Joaquim), Paraú (P.A Campos Belos, P.A Estrela do Oeste).

No território Açu-Mossoró a pesquisa foi desenvolvida nos municípios (comunidades) de: Areia Branca (Redonda e São Cristovão), Assu (Bela Vista do Piató e Poré), Baraúna (Vila Nova I), Grossos (Areia Alvas), Mossoró (Solidão, Vingt Rosado, Barreira Vermelha, Santa Rita, Bela Vista e São José I, além da comunidade de Barreira Vermelha e Sussuarana e Piquiri) e Serra do Mel (vila Maranhão e vila Bahia). 


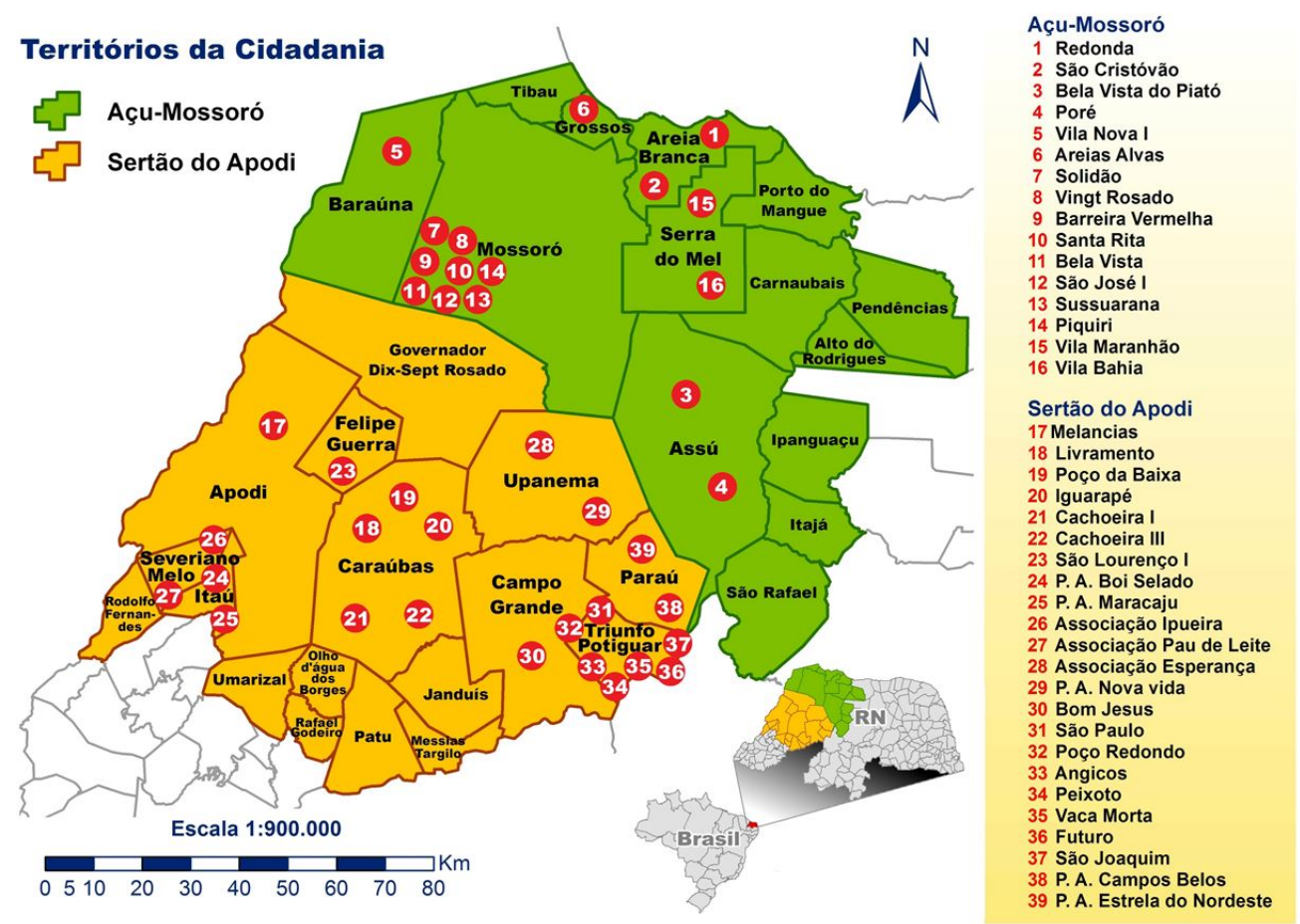

Figura 1. Territórios Açu-Mossoró e Sertão do Apodi e comunidades pesquisadas. Fonte: Brasil (2016).

Dessa forma, a pesquisa foi realizada com agricultores familiares alcançando um total de 39 comunidades rurais, sendo 16 delas do Território da Cidadania Açu-Mossoró e 23 comunidades do Território da Cidadania Sertão do Apodi, conforme mostrado na Figura 1. O período das entrevistas foi de 25 de novembro de 2010 a 23 de dezembro de 2010, e foram visitados 540 entrevistados, sendo 270 entrevistas em cada território.

\subsection{O Índice de Condições de Vida (ICV)}

Na concepção defendida pela Secretaria de Desenvolvimento Territorial (SDT/MDA), a perspectiva territorial do desenvolvimento rural é destacada como uma dinâmica que possibilita a integração dos espaços, dos atores, dos mercados e das políticas públicas numa arena de conflitos que convergem para o desenvolvimento de caráter mais endógeno. Mais ainda, conforme apontam Waquil et al. (2007), essa perspectiva defende que elementos como a igualdade, a diversificação e densidade econômica e social, a justiça social, o sentimento de pertencimento, valorização da história e da cultura locais e os processos de inclusão são importantes e devem ser constantemente perseguidos e alcançados, visando a necessidade de um ambiente favorável para que forças endógenas possam surgir e se propagar no território. E nesse contexto, a identidade ${ }^{5}$ é considerada fundamental para promover e afirmar a unidade territorial, levando os atores a convergirem para uma melhor negociação e êxito das políticas públicas. A partir desta perspectiva, conforme Rambo et al. (2012), foi para acompanhar a evolução das condições objetivas de autonomia e autogestão do território que surgiu a demanda pelo Índice de Condições de Vida (ICV) para ser aplicado nos territórios rurais.

A concepção do Índice de Condições de Vida (ICV) teve inspiração na contribuição teórica da obra Desenvolvimento como Liberdade, de Amartya Sen, e sua elaboração e estruturação das instâncias se deu a partir das contribuições metodológicas da pesquisadora Ângela Antônia Kageyama. No entanto, de acordo com Rambo et al. (2012), a metodologia do ICV é precedida de uma primeira experiência desenvolvida pela equipe de pesquisadores do programa de pós-

${ }^{5} \mathrm{~A}$ Identidade é um conceito que indica a condição social e o sentimento de pertencer a uma determinada cultura. De acordo com Perico (2009) e Nunes et al. (2019), representa um conjunto de características de um povo, oriundas da interação dos membros do território e da forma destes interagir com o mundo. Em um indivíduo, o nível de identidade territorial vai depender da sua participação ou exclusão relativa à cultura que o envolve. 
graduação em Desenvolvimento Rural da Universidade Federal do Rio Grande do Sul (PGDR/UFRGS), com o projeto de validação do Índice de Desenvolvimento Sustentável (IDS). O IDS passou a ser apresentado no formato de um Biograma, conforme em Sepúlveda (2005), e calculado por meio de dados secundários, considerando as dimensões comuns do desenvolvimento na análise do ICV: social, demográfica, político-institucional, econômica, ambiental e cultural. Cabe ressaltar, ainda, que, nos últimos anos, o ICV tem sido estudado por autores como Rambo et al. $(2012,2015)$, Casimiro et al. (2015), Bastian et al. (2016), Caniello (2016) e Toigo \& Conterato (2017).

Dessa forma, na perspectiva de monitorar as condições de vida, com base na percepção dos agricultores familiares nos territórios rurais, buscou-se um indicador de resultados capaz de corresponder às percepções no e por parte do público-alvo das políticas públicas implantadas nos territórios. Assim, o ICV, que também é um mecanismo de análise comparativa, passou a utilizar dados primários de questionários aplicados em domicílios rurais permitindo a atualização das informações com a frequência desejada. O ICV se mostrou, segundo Rambo et al. (2012), um instrumento simples que considera as características de multidimensionalidade do desenvolvimento, além das dimensões econômica, sociocultural, político-institucional e ambiental. Além da multidimensionalidade, a metodologia do ICV é baseada em três instâncias, conforme mostrado no Quadro 1) na perspectiva de Kageyama (2008).

A primeira se refere aos fatores condicionantes do desenvolvimento rural, na qual se procura identificar as diferentes bases de recursos territoriais sobre as quais se desenrola o processo de desenvolvimento rural. A segunda busca identificar as possíveis diferenças nas trajetórias do desenvolvimento e representa as características do desenvolvimento rural. E a terceira dimensão pressupõe os efeitos dos processos de desenvolvimento, admitindo que as características junto à base territorial diversa, ou seja, juntos aos fatores, produzem resultados econômicos e sociais também diversos. A seguir, podem ser observadas as instâncias e indicadores do Índice de Condições de Vida (ICV):

Quadro 1. Instâncias e indicadores das condições de vida das famílias rurais

\begin{tabular}{|c|c|}
\hline & $\begin{array}{l}\text { Mão de obra familiar em atividade dentro ou fora da } \\
\text { unidade }\end{array}$ \\
\hline \multirow{7}{*}{ Fatores do desenvolvimento } & Área da unidade de produção familiar \\
\hline & Escolaridade \\
\hline & Condições da moradia \\
\hline & Acesso a mercados \\
\hline & Acesso a políticas públicas \\
\hline & Acesso a crédito e assistência técnica \\
\hline & Presença de instituições que favorecem o desenvolvimento rural \\
\hline \multirow{7}{*}{$\begin{array}{l}\text { Características do } \\
\text { desenvolvimento }\end{array}$} & Renda familiar \\
\hline & Produtividade do trabalho \\
\hline & Diversificação da produção agrícola \\
\hline & Pluriatividade, diversificação nas fontes de renda familiar \\
\hline & Uso e preservação dos recursos naturais: água \\
\hline & Uso e preservação dos recursos naturais: solo \\
\hline & Uso e preservação dos recursos naturais: vegetação nativa \\
\hline \multirow{5}{*}{ Efeitos do desenvolvimento } & Estar bem alimentado \\
\hline & Ter boa saúde \\
\hline & Permanência dos membros da família da unidade de produção \\
\hline & Percepção sobre as mudanças na situação econômica da família \\
\hline & Percepção sobre as mudanças na situação ambiental da unidade \\
\hline
\end{tabular}

Fonte: Brasil (2011).

Para obter o ICV dos territórios são seguidos três passos, nos quais são utilizados os dados primários coletados dos questionários aplicados nos domicílios dos territórios rurais. 
Passo 1 - média aritmética de cada indicador $\left(m_{i}\right)$, em cada instância.

$$
m_{i}=\frac{\sum_{k=1}^{k_{\max }} i_{i k}}{k_{\max }}
$$

Em que $i=1$ a 8 (instância 1); $i=9$ a 16 (instância 2); $i=17$ a 24 (instância 3), sendo $k_{m m}$ quantidade de questionários aplicados com respostas válidas do indicador $i$.

Passo 2 - média aritmética dos oito indicadores de cada $\left(m_{i}\right)$.

$$
\begin{aligned}
& d_{1}=\frac{m_{1}+m_{2}+m_{3}+m_{4}+m_{5}+m_{6}+m_{7}+i_{8}}{8} \\
& d_{2}=\frac{m_{9}+m_{10}+m_{11}+m_{12}+m_{13}+m_{14}+m_{15}+i_{16}}{8} \\
& d_{3}=\frac{m_{17}+m_{18}+m_{19}+m_{20}+m_{21}+m_{22}+m_{23}+i_{24}}{8}
\end{aligned}
$$

Passo 3 - média harmônica das instâncias (ICV).

$$
\mathrm{ICV}=\frac{3}{\frac{1}{d_{1}}+\frac{1}{d_{2}}+\frac{1}{d_{3}}}
$$

\section{Resultado e discussão}

\subsection{O Índice de Condições de Vida (ICV) do Território Açu-Mossoró}

Seguindo cada um dos três passos acima, quando calculadas as médias de cada subitem o resultado para o indicador é a média dos dois subitens, e as médias dos indicadores e o ICV calculado são representados em gráficos do tipo Biograma, conforme Figura 2. No caso específico do Território Açu-Mossoró, o resultado do ICV (em escala que varia de 0 a 1 ) revelou um índice de 0,534, demonstrando um nível de qualidade de vida considerado médio.

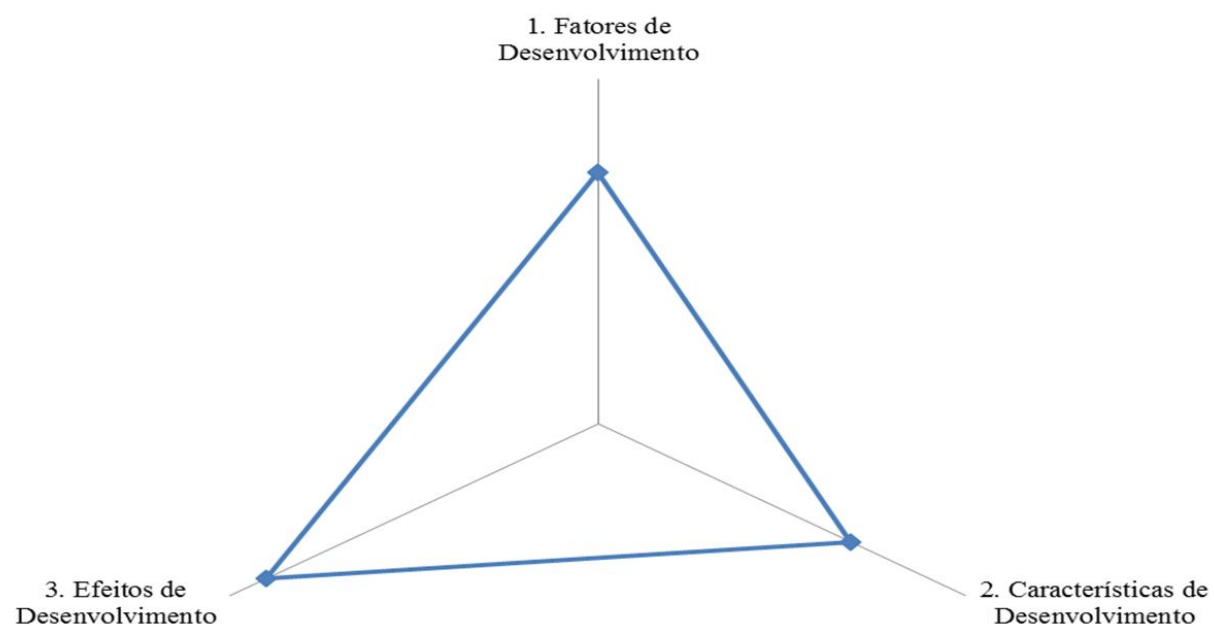

Figura 2. Território Açu-Mossoró: Biograma do Índice de Condições de Vida (ICV) ICV: 0,534. Fonte: Brasil (2012b). 
Conforme mostra o Quadro 2, a pesquisa revelou que a média da primeira instância foi de 0,512, índice considerado relativamente baixo em comparação com ICV 0,534. Essa instância mostra claramente as áreas onde estão sendo destinados os recursos das políticas públicas implantadas. Na segunda instância, a média foi de 0,481, a mais baixa das três, considerando que esta instância busca identificar as possíveis diferenças nas trajetórias do desenvolvimento rural. $\mathrm{E}$, por fim, a média da terceira instância atingiu 0,633, a mais alta das três, sendo que essa instância pressupõe os efeitos dos processos de desenvolvimento, admitindo que as características junto à base de recursos territorial diversa, ou seja, juntos aos fatores, produzem retornos e reflexos econômicos e sociais também diversos.

Pesquisa realizada por Caniello (2016) ressalta que a agricultura familiar no Brasil teve um papel decisivo no processo de dinamização dos territórios e levou à ampliação do mercado interno, ao revigoramento do setor produtivo, a uma ascensão social extraordinária e, em decorrência disso tudo, à inclusão social com melhoria das condições de vida.

Quadro 2. Território Açu-Mossoró: O ICV e suas instâncias de desenvolvimento

\begin{tabular}{|c|c|c|c|}
\hline \multicolumn{3}{|c|}{ Quadro de Indicadores } & \multirow{5}{*}{$\begin{array}{c}\text { Legenda } \\
0,00-0,20=\text { Baixo } \\
0,20-0,40=\text { Médio Baixo } \\
0,40-0,60=\text { Médio } \\
0,60-0,80=\text { Médio Alto } \\
0,80-1,00=\text { Alto }\end{array}$} \\
\hline ÍNDICE DE CONDIÇÕES DE VIDA (ICV) & 0,534 & Médio & \\
\hline 1. Fatores de desenvolvimento & 0,512 & Médio & \\
\hline 2. Características de desenvolvimento & 0,481 & Médio & \\
\hline 3. Efeitos de desenvolvimento & 0,633 & Médio Alto & \\
\hline
\end{tabular}

Fonte: Brasil (2012b).

Assim, a partir do cálculo do ICV e de suas três instâncias foram calculadas as médias de cada subitem (numa escala que varia de 0 a 1), e o resultado para o indicador é a média dos subitens, conforme Tabela 1. Quanto ao indicador da primeira instância do território Açu-Mossoró, no que diz respeito aos seus subitens, os cinco primeiros alcançaram médias superiores ao indicador, e os cinco últimos, médias inferiores. Na média dos subitens chama a atenção para o nível de "Escolaridade" no território com um índice relativamente alto, de 0,569, comparado à média de 0,512 da instância. No entanto, a partir dos números da pesquisa quando se observa o número de pessoas maiores de 15 anos alfabetizadas, nota-se que apenas $53,70 \%$ são alfabetizadas e $46,29 \%$ não, o que revela um quadro preocupante e sugere uma fragilidade em um subitem essencial, considerando que é nessa instância que são destinados os recursos das políticas e onde se desenrola o processo de desenvolvimento rural.

Nessa mesma direção, os resultados obtidos na pesquisa corroboram com Caniello (2016) que, após estudar uma amostra de 37 territórios da cidadania no Brasil, verificou que, a educação no meio rural apresenta-se como precaríssima, pois, embora 90,3\% das crianças frequentem a escola, a taxa de analfabetismo entre adultos é de $35,4 \%$ e apenas $17,1 \%$ dos maiores de 15 anos têm o Ensino Fundamental completo. Já Casimiro et al. (2014, p. 09), em pesquisa no território da Reforma, Mato Grosso do Sul, observaram dados diferentes do território Açu-Mossoró; dos 250 estabelecimentos entrevistados, pelos autores 91\% dos adolescentes em idade escolar estavam matriculados. Entre os agricultores familiares essa porcentagem era ainda maior, com $96 \%$. "Esse resultado pode se justificar pela exigência do governo que obriga todas as crianças e adolescentes em idade escolar estarem regularmente matriculados, requisito para participar e receber o benefício do programa bolsa-família" (Casimiro et al., 2015, p. 9).

Segundo os autores, quando se comparam os agricultores familiares e os não familiares, os não familiares são mais alfabetizados. Nesse caso, Casimiro et al. (2015) afirmam que diferentes fatores permitem entender esse resultado, tais como a condição financeira, geralmente melhor nos agricultores não familiares. Porém, o indicador de destaque dessa primeira dimensão é, na verdade, a maior das médias, ou seja, as "condições de moradia", que alcançou 0,647 no território Açu-Mossoró. De acordo com as percepções dos entrevistados, considerando que cada quesito para estes subitens é registrado em uma escala 
de 1 a 5 , de $1=$ éssimo para 5=ótimo ou variações dessa escala, a maioria das respostas sobre as condições da estrutura das residências rurais foi "Bom" e "Ótimo". Essa percepção dos entrevistados corrobora com a análise de Sen (2000), em que o autor atenta-se especialmente para a expansão das "capacidades" das pessoas de levar o tipo ou estilo de vida que elas, independente de qualquer coisa, valorizam. Nos 37 territórios da amostra estudada por Caniello (2016), no que tange à permanência dos membros da família na unidade produtiva familiar, ao estado nutricional da família, à sua condição econômica, às condições de moradia e, também, à saúde, obteve índice de 0,5832, com 51,5\% avaliações positivas e apenas 16,4\% negativas.

Tabela 1. Território Açu-Mossoró: Instância Fatores do Desenvolvimento e indicadores das condições de vida das famílias rurais

$\begin{array}{cccccc}\text { 2. DIMENSÃo 1: fatores do desenvolvimento } & \mathbf{0 , 5 1 2} & \text { Freq. } & \text { Mínimo } & \text { Máximo } & \begin{array}{c}\text { Desvio } \\ \text { Padrão }\end{array} \\ \text { 1.1. Número de famílias trabalhando } & 0,549 & 162 & 0,000 & 1,000 & 0,326 \\ \text { 1.2. Mão de obra familiar } & 0,583 & 162 & 0,000 & 1,000 & 0,337 \\ \text { 2. Área utilizada para produção } & 0,549 & 162 & 0,000 & 1,000 & 0,334 \\ \text { 3. Escolaridade } & 0,569 & 162 & 0,000 & 1,000 & 0,344 \\ \text { 4. Condições de moradia } & 0,647 & 162 & 0,000 & 1,000 & 0,367 \\ \text { 5. Acesso aos mercados } & 0,506 & 162 & 0,000 & 1,000 & 0,308 \\ \text { 6. Programas do Governo } & 0,418 & 162 & 0,000 & 1,000 & 0,293 \\ \text { 7.1. Acesso a crédito } & 0,384 & 162 & 0,000 & 1,000 & 0,278 \\ \text { 7.2. Acesso a assistência técnica } & 0,394 & 162 & 0,000 & 1,000 & 0,277 \\ \text { 8. Presença de instituições } & 0,454 & 162 & 0,000 & 1,000 & 0,312\end{array}$
Fonte: Brasil (2012b).

Por fim, três indicadores chamam a atenção por apresentar as menores médias da dinâmica Fatores de desenvolvimento do território Açu-Mossoró, pois, quando integrados, esses três indicadores formam um tripé de significativa importância para a dinâmica do desenvolvimento rural: o "Acesso aos mercados" com média de 0,506, "Acesso a crédito" com 0,384 (o mais baixo de todos), e "Acesso à assistência técnica" com 0,394 . Segundo a percepção dos entrevistados, o acesso dos agricultores familiares ao crédito é considerado em sua maioria ruim, pois $40,74 \%$ dos que responderam revelaram ser complicado o acesso, e 14,81\% consideram o acesso muito complicado. Esse dado vai de encontro com o Plano Territorial de Desenvolvimento Rural Sustentável PTDRS (Brasil, 2010) do Território Açu-Mossoró, pois, neste Plano, nos últimos anos, o acesso ao crédito vem melhorando, principalmente por meio do Programa Nacional de Apoio à Agricultura Familiar (Pronaf).

O "Acesso à assistência técnica", que associado ao crédito convergem para uma maior dinâmica do desenvolvimento rural e, consequentemente, possibilita o ajuste das técnicas e o surgimento de tecnologias, se apresentou como a segunda menor média, atrás apenas do "Acesso a crédito". Esse resultado revela a relação que estas têm entre si, o que afirmam a consequência negativa que é o reduzido desempenho do "Acesso aos mercados". Graficamente, esses subitens estão representados no Biograma da instância, visto na Figura 3. 


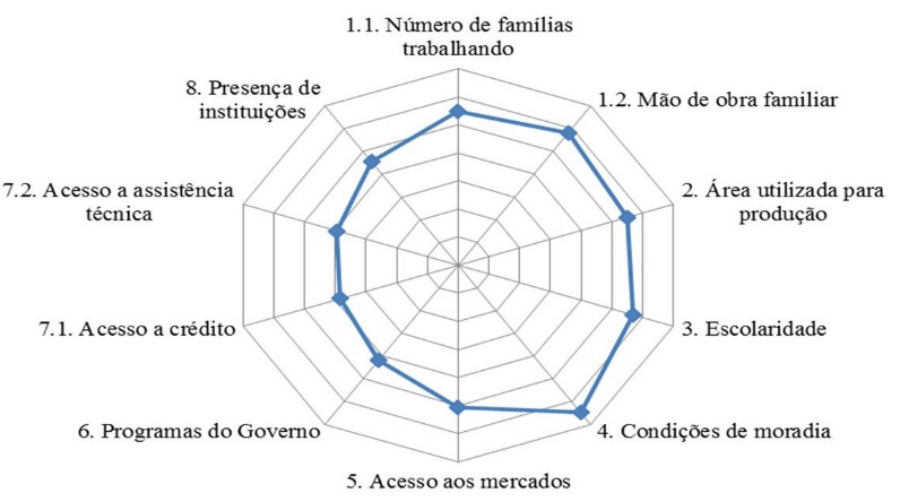

Figura 3. Açu-Mossoró: Biograma representativo da instância Fatores do Desenvolvimento Fonte: Brasil (2012b).

Ao considerar as atividades capazes de dinamizar o Território Açu-Mossoró, a pesquisa mostrou que nem sempre o desenvolvimento tem alicerçado características que universalizam a melhoria das condições de vida dos indivíduos. E na análise da instância "Características de desenvolvimento", as dimensões "Renda familiar" com média 0,489 e a "Diversificação nas fontes de renda familiar", com 0,394 (esta última a mais baixa), revelam uma fragilidade por se configurar nas médias mais baixas, conforme Tabela 2. Durante a coleta de dados para a composição do ICV, foi recorrente captar na percepção dos agricultores familiares a insatisfação sobre a composição e diversificação da sua renda, ou seja, a renda familiar é constituída basicamente de poucas fontes, especialmente da produção agrícola, de transferência de renda e da aposentadoria. Segundo os entrevistados, é a natureza e o tipo das fontes que não se traduz numa renda final satisfatória, pois têm valores baixos e insuficientes.

Esta instância, ou elementos de conversão, tem como finalidade identificar diferenças nas trajetórias do desenvolvimento rural, porém, possui, no seu fator econômico mais evidente, ou seja, na renda, uma fragilidade que implica diretamente nas condições de vidas das famílias. Considerando a existência de domicílios que têm mais de cinco pessoas, alguns entrevistados admitiram que a renda final não era suficiente para custear todas as despesas familiares durante o mês. Por outro lado, as dimensões mais elevadas dessa instância, segundo a percepção dos indivíduos do Território Açu-Mossoró, foram a "Preservação da mata nativa", com 0,551, seguida da "Conservação da área de produção: solo", com 0,545, da "Produtividade da terra", com 0,517, e da "Produtividade do trabalho", com 0,509, essas com médias consideradas ainda baixas e próximas do índice do ICV.

Tabela 2. Território Açu-Mossoró: instância e indicadores das condições de vida

\begin{tabular}{|c|c|c|c|c|c|}
\hline $\begin{array}{c}3 \text { - DIMENSÃO 2: características do } \\
\text { desenvolvimento }\end{array}$ & 0,481 & Freq. & Mínimo & Máximo & $\begin{array}{l}\text { Desvio } \\
\text { Padrão }\end{array}$ \\
\hline 9. Renda familiar & 0,489 & 162 & 0,000 & 1,000 & 0,312 \\
\hline 10. Produtividade do trabalho & 0,509 & 162 & 0,000 & 1,000 & 0,311 \\
\hline 11. Produtividade da terra & 0,517 & 162 & 0,000 & 1,000 & 0,311 \\
\hline 12. Diversificação da produção agrícola & 0,438 & 162 & 0,000 & 1,000 & 0,303 \\
\hline 13. Diversificação nas fontes de renda familiar & 0,394 & 162 & 0,000 & 1,000 & 0,273 \\
\hline 14. Conservação das fontes de água & 0,401 & 162 & 0,000 & 1,000 & 0,316 \\
\hline 15. Conservação da área de produção: solo & 0,545 & 162 & 0,000 & 1,000 & 0,327 \\
\hline 16. Preservação da vegetação nativa & 0,551 & 162 & 0,000 & 1,000 & 0,341 \\
\hline
\end{tabular}
Fonte: Brasil (2012b).

Cabe ressaltar, na análise dessa instância, que as três dimensões que mais diretamente se relacionam e influenciam na composição da renda, ou seja, as dimensões "Produtividade da terra", "Produtividade do trabalho" e a "Diversificação da produção agrícola", têm médias 
consideradas baixas. Isso sugere, a partir da percepção dos indivíduos, um baixo rendimento da atividade agrícola, e, consequentemente, uma baixa produtividade e pouca capacidade das unidades familiares de produção de gerar riqueza e de garantir condições de vida para a maioria das pessoas do meio rural do Território Açu-Mossoró. Graficamente, esses subitens estão representados no biograma da instância, visto na Figura 4.

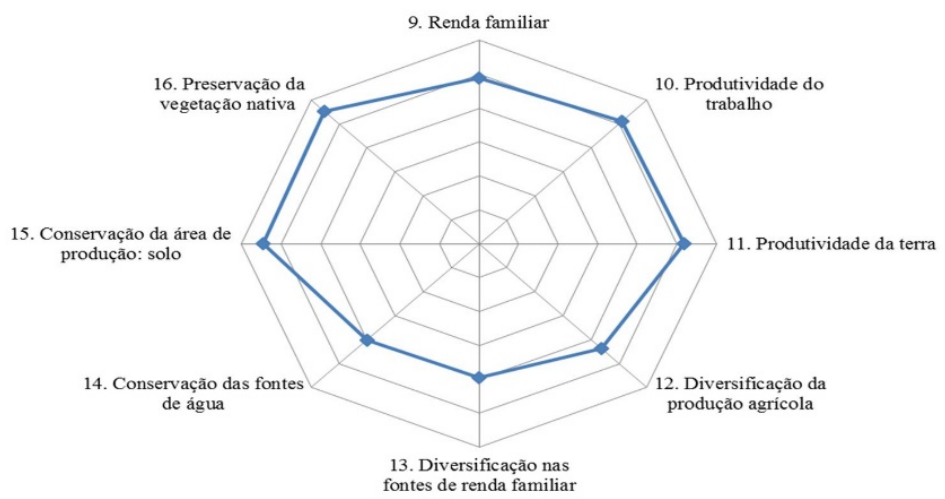

Figura 4. Território Açu-Mossoró: Biograma representativo da instância Características do Desenvolvimento Fonte: Brasil (2012b).

Sobre a instância "Efeitos de desenvolvimento" do Território Açu-Mossoró, é possível entender como sendo os resultados econômicos e sociais possibilitados pelas políticas públicas territoriais destinadas ao desenvolvimento rural. Esse efeito pode ser visualizado através do indicador considerado satisfatório, ou seja 0,633, estando acima do ICV, de 0,534 para o território. De acordo com a Tabela 3, podemos verificar que a dimensão “Permanência dos familiares nos domicílios" apresentou um indicador considerado alto, 0,854, que representa um aspecto de ruralidade - segundo a percepção da maioria dos indivíduos, viver no meio rural é o que eles pretendem, e não há interesse em migrar. O segundo indicador mais alto foi "Situação econômica", com 0,648, classificado como médio, apesar de ter sido observado na pesquisa de campo uma agricultura familiar muito frágil, uma quantidade significativa de aposentados rurais, uma presença considerável de rendas não agrícolas, bem como uma presença pequena de jovens.

Tabela 3. Território Açu-Mossoró: Instância Efeitos do Desenvolvimento e indicadores das condições de vida das famílias rurais

\begin{tabular}{|cccccc} 
4- DIMENSÃo 3: efeitos do desenvolvimento & $\mathbf{0 , 6 3 3}$ & Freq. & Mínimo & Máximo & $\begin{array}{c}\text { Desvio } \\
\text { Padrão }\end{array}$ \\
\hline 17. Condições de alimentação e nutrição & 0,636 & 270 & 0,000 & 1,000 & 0,206 \\
18. Condições de saúde & 0,613 & 270 & 0,000 & 1,000 & 0,235 \\
19. Permanência dos familiares no domicílio & 0,854 & 270 & 0,000 & 1,000 & 0,195 \\
20. Situação econômica & 0,648 & 270 & 0,000 & 1,000 & 0,202 \\
21. Situação ambiental & 0,568 & 270 & 0,000 & 1,000 & 0,205 \\
22. Participação em organizações comunitárias & 0,602 & 270 & 0,000 & 1,000 & 0,251 \\
23. Participação política & 0,619 & 270 & 0,000 & 1,000 & 0,252 \\
24. Parciticipação em atividades culturais & 0,521 & 270 & 0,000 & 1,000 & 0,296 \\
\hline
\end{tabular}

Fonte: Brasil (2012b).

As dimensões que se apresentaram com as médias mais baixas foram "Participação em atividades culturais", "Situação ambiental", com 0,521 e 0,568, respectivamente, mostrando uma percepção dos indivíduos de certa forma negativa quanto a essas duas dimensões. Essas dimensões refletem o bem-estar dentro dos significados de desenvolvimento, especialmente os relacionados com distribuição e maior acesso à riqueza, inclusão produtiva, equidade, 
sustentabilidade, autonomia etc., e se constata na percepção dos entrevistados aspectos positivos em praticamente todas elas. Por mais que seja subjetiva, a pesquisa revelou uma percepção otimista quanto aos "Efeitos de desenvolvimento", em que muitos entrevistados se revelaram satisfeitos com suas "Condições de alimentação" $(0,636)$, com as "Condições de saúde" $(0,613)$ e com a "Participação política" $(0,619)$. Graficamente, os subitens desta instância estão representados no Biograma da instância, visto na Figura 5.

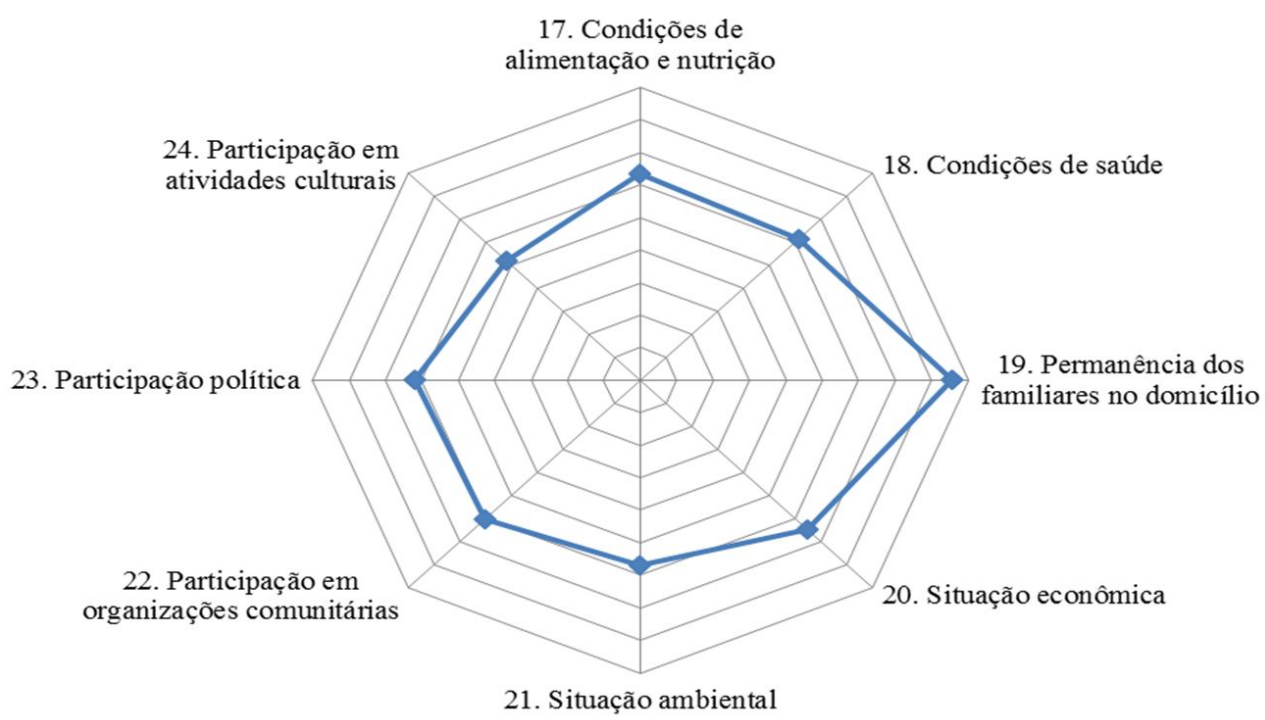

Figura 5. Território Açu-Mossoró: Biograma representativo da instância “Efeitos de Desenvolvimento" Fonte: Brasil (2012b).

A pesquisa mostrou que os agricultores familiares percebem os efeitos de maneira mais significativa em relação ao universo pesquisado, e indícios para explicar tal resultado podem estar na própria característica da agricultura familiar, vista basicamente pela sua diversificação dos seus modos de vida. Cabe ressaltar que, aqui, os significados do desenvolvimento não se limitam a fatores meramente econômicos, como a renda, o produto e o lucro. Na verdade, e a priori, ativos e capitais diversos aliados a fatores não econômicos, a exemplo das liberdades e das capacidades individuais, podem se expressar em estratégias de reprodução tanto econômica como social. Todavia, apesar de o índice obtido ser alto, cabe considerar a sua relação com os "Fatores" e com as "Características de desenvolvimento".

Pesquisa semelhante foi realizada no território Zona Sul, Rio Grande do Sul, por Bastian et al. (2016), que apontam que a percepção dos entrevistados acerca dos "feitos ou dos funcionamentos do desenvolvimento" é a que obteve o melhor resultado $(0,644)$, assim como no Açu-Mossoró $(0,633)$, em relação às "características do desenvolvimento ou elementos de conversão" $(0,576)$; uma média mais alta que o Território Açu-Mossoró que apresenta $(0,481)$; já os "fatores do desenvolvimento ou intitulamentos " mostram média de $(0,544)$, semelhante à do Território Açu-Mossoró que apresenta $(0,512)$. Para os autores isto indica, a priori, que não há uma correspondência direta entre fatores, características e efeitos do desenvolvimento, no sentido de que a existência de ativos e capitais aliados às liberdades individuais se traduz em mudanças significativas nas condições de vida, embora essa percepção seja algo que varia substancialmente entre os indivíduos ou famílias.

\subsection{O Índice de Condições de Vida (ICV) do Território Sertão do Apodi}

Como visto acima, o ICV é calculado com base na agricultura familiar com e sem produção, e as médias dos indicadores e o ICV calculado são representados em gráficos do tipo Biograma, conforme Figura 6. Neste caso, o ICV encontrado para o Território Sertão do Apodi foi de 0,569 (superior ao encontrado para o Território Açu-Mossoró), considerado médio, de acordo com o quadro de indicadores apresentado a seguir. 


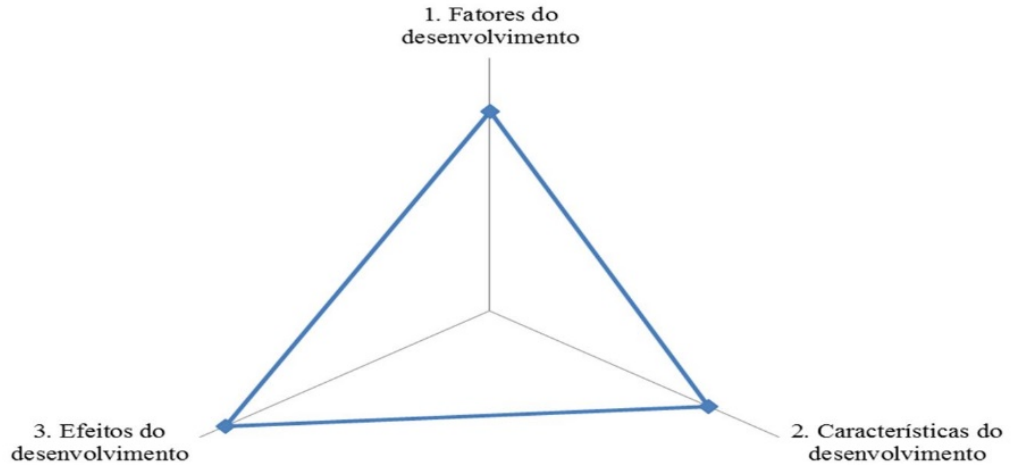

Figura 6. Território Sertão do Apodi: Biograma do Índice de Condições de Vida (ICV) ICV: 0,569

Fonte: Brasil (2012a).

Considerando que os "Fatores de Desenvolvimento" têm como finalidade mostrar as áreas para onde os recursos financeiros das políticas territoriais estão sendo direcionados, a pesquisa revelou um indicador de 0,553, que, na escala de 0 a 1 , é considerado médio, conforme Quadro 3. Da mesma forma, na segunda instância, as "Características de desenvolvimento", o indicador foi de 0,527, o mais baixo das três, que busca identificar as principais diferenças nas trajetórias do desenvolvimento rural. E, por fim, a terceira instância alcançou o indicador 0,638, o mais alto das três, sendo que os "Efeitos do desenvolvimento" admite que as características associadas com a infraestrutura territorial diversa representam os resultados das políticas territoriais a partir dos reflexos econômicos e sociais diversos.

Quadro 3. Território Sertão do Apodi: O ICV e suas instâncias de desenvolvimento

\begin{tabular}{|c|c|c|c|}
\hline \multicolumn{3}{|c|}{ Quadro de Indicadores } & Legenda \\
\hline ÍNDICE DE CONDIÇÕES DE VIDA (ICV) & 0,569 & Médio & $0,00-0,20=$ Baixo \\
\hline 1. Fatores de desenvolvimento & 0,553 & Médio & $0,20-0,40=$ Médio Baixo \\
\hline 2. Características de desenvolvimento & 0,527 & Médio & $\begin{array}{c}0,40-0,60=\text { Medio } \\
060-080=\text { Médio Alto }\end{array}$ \\
\hline 3. . Efeitos de desenvolvimento & 0,638 & Médio Alto & $0,80-1,00=$ Alto \\
\hline
\end{tabular}

Fonte: Brasil (2012a).

Cabe ressaltar que, tanto no Território Açu-Mossoró como no Sertão do Apodi, os fatores e as características do grupo de agricultores familiares estão abaixo da média geral do ICV, e os efeitos encontram-se acima. Isso sugere que os acessos ou os ativos dos agricultores familiares são frágeis e estão em condições piores do que dos demais entrevistados.

Analisando as dimensões que compõe o ICV do Território Sertão do Apodi, a pesquisa identificou parâmetros com valores bem abaixo do ICV, como é o "Acesso a assistência técnica" e o "Acesso ao crédito", que apresentaram as médias mais baixas, ou seja, 0,380 e 0,454 , respectivamente. Na percepção dos entrevistados do Território Sertão do Apodi, assim como no Açu-Mossoró, o acesso dos agricultores familiares ao crédito é considerado, em sua maior parte, ruim. Isso reforça a fragilidade nas ações públicas visando o apoio efetivo aos agricultores familiares, além de uma ausência e deficiência de estrutura de produção e de organização coletiva, pois associado ao crédito os serviços de assistência técnica convergem para a dinamização dos territórios e, consequentemente, para o desenvolvimento rural.

Esse resultado revela a relação que estas dimensões têm entre si, reforçando outro aspecto negativo que é o pouco desempenho da dimensão "Acesso aos mercados". Pela observação das dimensões, conforme Tabela 4, a pesquisa mostra que a maior parte dos elementos de composição do ICV revela índice acima de 0,400, o que sugere e retrata que houve melhoria nas condições de vida das famílias residentes no território. Entre as principais dimensões com elevado indicador destaca-se a "Escolaridade" $(0,646)$, "Condições de moradia" $(0,636)$ e "Área utilizada para a produção agrícola" $(0,612)$. No que refere à 
escolaridade, pesquisa realizada por Casimiro et al. (2015) aponta que os produtores familiares do território da Reforma, Mato Grosso do Sul, têm um nível de formação e escolaridade baixo, mas esse nível está melhorando entre os jovens, pois a maioria está alfabetizada e regularmente matriculada. No caso do Território Sertão do Apodi é perceptível que há também melhorias em relação ao nível de escolaridade.

Para Casimiro et al. $(2015$, p. 9), “[...] no passado a importância dos estudos e a facilidade em estudar eram bem diferentes. O pai queria que o filho ajudasse nas atividades do campo, sem preocupação com os estudos". Assim, atualmente, a percepção acerca da importância com o nível de escolaridade é maior do que no passado. A educação é um fator importante, pois permite que as pessoas adotem tecnologias mais modernas e complexas e atinjam melhores níveis de produção, produtividade e de renda.

Tabela 4. Território Sertão do Apodi: Instância Fatores do Desenvolvimento e indicadores das condições de vida das famílias rurais

\begin{tabular}{cccccc} 
2. DIMENSÃo 1: fatores do desenvolvimento & $\mathbf{0 , 5 5 3}$ & Freq. & Mínimo & Máximo & $\begin{array}{c}\text { Desvio } \\
\text { Padrão }\end{array}$ \\
1.1. Número de famílias trabalhando & 0,543 & 241 & 0,000 & 1,000 & 0,287 \\
1.2. Mão de obra familiar & 0,595 & 241 & 0,000 & 1,000 & 0,283 \\
2. Área utilizada para produção & 0,612 & 241 & 0,000 & 1,000 & 0,281 \\
3. Escolaridade & 0,646 & 241 & 0,000 & 1,000 & 0,290 \\
4. Condições de moradia & 0,636 & 241 & 0,000 & 1,000 & 0,284 \\
5. Acesso aos mercados & 0,497 & 241 & 0,000 & 1,000 & 0,282 \\
6. Programas do governo & 0,464 & 234 & 0,000 & 1,000 & 0,325 \\
7.1. Acesso a crédito & 0,454 & 241 & 0,000 & 1,000 & 0,298 \\
7.2. Acesso a assistência técnica & 0,380 & 241 & 0,000 & 1,000 & 0,284 \\
8. Presença de instituições & 0,581 & 241 & 0,000 & 1,000 & 0,328 \\
\hline
\end{tabular}

Fonte: Brasil (2012a).

Como citado anteriormente, a ênfase é dada para a dimensão "Acesso a assistência técnica" que apresenta o menor índice, e esse indicador no Território Sertão do Apodi é baixo, apesar da presença em todo o território do Instituto Estadual de Assistência Técnica e Extensão Rural (Emater), das secretarias municipais de Agricultura, além da presença e intensa atuação do projeto Dom Helder Câmara (PDHC), que, desde o início dos anos 2000, atua em 10 municípios realizando serviços de assessoramento técnico. Graficamente, os subitens desta instância estão representados no Biograma da instância, visto na Figura 7.

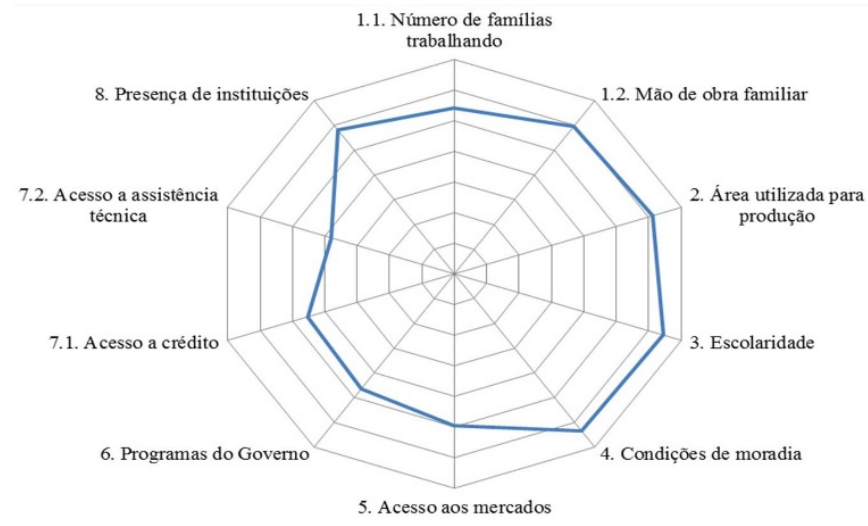

Figura 7. Território Sertão do Apodi: Biograma representativo da Instância Fatores do Desenvolvimento Fonte: Brasil (2012a).

Nessa direção, Casimiro et al. (2015) afirmam que, no território da Reforma (MS), uma das características da agricultura familiar é a ausência de organização entre os produtores. 
Predomina a visão individualista em que cada produtor procura o melhor comprador e preço para seus produtos. Os autores verificaram que $78 \%$ dos produtores familiares estudados afirmaram nunca ter vendido seus produtos para cooperativas ou associações, enquanto $89 \%$ dos produtores não familiares afirmaram o mesmo. $O$ que pode remeter à conclusão que $a$ organização dos produtores familiares para acesso ao crédito, produção e comercialização ainda é um desafio a ser superado em diferentes regiões do Brasil.

Dentro da dimensão "Características de desenvolvimento", há indícios de correlação entre a "Renda familiar" e a "Diversificação nas fontes de renda familiar", sejam monetárias ou não. Através da pesquisa é possível verificar que a diversificação nas fontes de renda familiar apresenta índice de 0,411 , bem próximo ao da renda familiar, que é de 0,463 , sendo estes os mais baixos desta dimensão do Território Sertão do Apodi, conforme Tabela 5, o que coincide nessas mesmas dimensões com o Território Açu-Mossoró. Percebe-se certa contradição na relação entre escolaridade da dimensão "Fatores de desenvolvimento" com índice elevado e a renda familiar, bem como a diversificação de suas fontes constante da dimensão características do desenvolvimento com índice relativamente baixo.

Neste sentido, chamam a atenção os dados da pesquisa no território Sertão do Apodi, onde a renda familiar e a escolaridade apresentam uma relação inversamente proporcional, ou seja, na medida em que se tem nos Fatores de Desenvolvimento na Tabela 4 acima o indicador escolaridade como o maior $(0,646)$, tem-se na Tabela 5 abaixo, das Características do Desenvolvimento, o indicador diversificação das fontes de renda como o mais baixo $(0,411)$. Contudo, a própria metodologia da pesquisa desenvolvida aponta uma justificativa para essa questão. Primeiro, os dados apresentados fundamentam-se na percepção das famílias entrevistadas que, em sua maioria, mensura o grau de escolaridade a partir da comparação do acesso à escola que tem hoje em relação ao que existia em anos anteriores.

Autores como Casimiro et al. (2015) apresentam dados da pesquisa realizada no território da Reforma (MS), na qual foi encontrado o percentual de $97 \%$ dos produtores familiares que conseguem se manter com produção agropecuária própria, enquanto que $60 \%$ dos produtores não familiares entrevistados buscam complementar sua renda com trabalhos agropecuários para terceiros. Um dos motivos que podem explicar a alta porcentagem de produtores não familiares no trabalho para terceiros é a classificação inadequada do agricultor familiar. Um dos requisitos da legislação vigente é que $80 \%$ da renda seja oriunda do próprio estabelecimento, o que significa, para um pequeno produtor que não consegue sua subsistência no próprio estabelecimento e busca por outra fonte de renda, de ser classificado como produtor não familiar.

Tabela 5. Território Sertão do Apodi: Instância Características do Desenvolvimento e indicadores das condições de vida das famílias rurais

\begin{tabular}{cccccc} 
3 - DIMENSÃo 2: características do & $\mathbf{0 , 5 2 7}$ & Freq. & Mínimo & Máximo & $\begin{array}{c}\text { Desvio } \\
\text { Padrão }\end{array}$ \\
$\begin{array}{c}\text { 9esenvolvimento } \\
\text { 9. Renda familiar }\end{array}$ & 0,463 & 241 & 0,000 & 1,000 & 0,270 \\
10. Produtividade do trabalho & 0,510 & 241 & 0,000 & 1,000 & 0,266 \\
11. Produtividade da terra & 0,594 & 241 & 0,000 & 1,000 & 0,296 \\
12. Diversificação da produção agrícola & 0,501 & 241 & 0,000 & 1,000 & 0,283 \\
13. Diversificação nas fontes de renda familiar & 0,411 & 241 & 0,000 & 1,000 & 0,273 \\
14. Conservação das fontes de água & 0,549 & 241 & 0,000 & 1,000 & 0,327 \\
15. Conservação da área de produção: solo & 0,609 & 241 & 0,000 & 1,000 & 0,288 \\
16. Preservação da vegetação nativa & 0,577 & 241 & 0,000 & 1,000 & 0,311 \\
\hline
\end{tabular}

Fonte: Brasil (2012a).

Ainda em relação à esta dimensão do ICV destacam-se duas características que apresentam melhores indicadores: a "Conservação da área de produção: solo", com 0,609, e a "Produtividade da terra", com índice de 0,594, dados que revelam o potencial produtivo da agricultura familiar do território. As demais dimensões, ou seja, "Produtividade do trabalho", "Diversificação da produção agrícola", "Conservação das fontes de água" e "Preservação da 
mata nativa" possuem médias próximas, inclusive do indicador do ICV. Graficamente, os subitens desta instância estão representados no Biograma da instância, visto na Figura 8. Em relação à instância "Características do desenvolvimento", no estudo realizado por Caniello (2016) para analisar o ICV em 37 territórios brasileiros, apresenta que se destacam dois quesitos: (1) "uso e preservação dos recursos naturais: água", com 0,6113 e 60\%; e (2) "uso e preservação dos recursos naturais: solo", com 0,6036 e 53\%.

Estudo semelhante foi realizado por Toigo \& Conterato (2017) nos 25 municípios que fazem parte do Território Zona Sul, no Rio Grande do Sul, e aponta que o indicador referente à diversificação das fontes de renda das famílias foi o mais baixo da dimensão 2, que apresenta as características do desenvolvimento, o conjunto geral dos indicadores da dimensão 2 ficou equivalente a 0,576, ou seja, recebeu um critério avaliativo "médio" no Território Zona Sul (RS), bem próximo do Território Sertão do Apodi, com média de 0,527 na dimensão 2 do ICV. Para Toigo \& Conterato (2017, p. 271), "a pluralidade dos Índices de Condições (ICV) contribui para apreender questões muitas vezes esquecidas ou ignoradas nos debates a respeito do desenvolvimento.

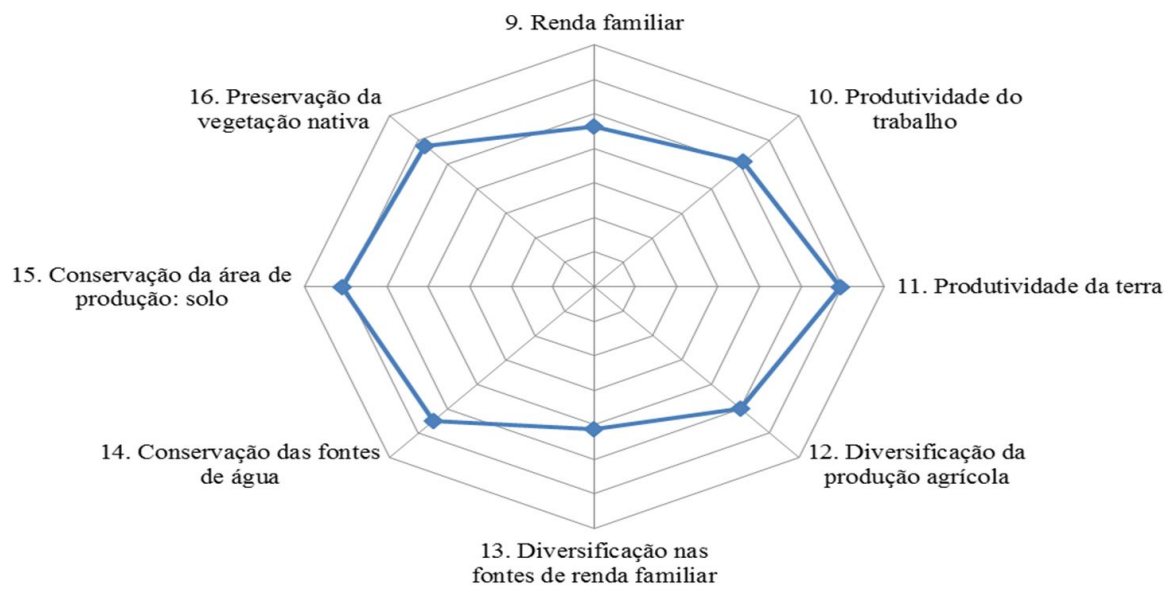

Figura 8. Território Sertão do Apodi: Biograma representativo da instância Características do Desenvolvimento Fonte: Brasil (2012a).

Por fim, na última dimensão estrutural do ICV do Território Sertão do Apodi, está o melhor indicador na dimensão "Permanência dos familiares no domicílio", com $(0,833)$, conforme Tabela 6, repetindo a mesma lógica do Território Açu-Mossoró. Do outro lado, na relação das famílias com a dimensão "Participação em atividades culturais", o índice é o mais baixo $(0,490)$, demonstrando a deficiência e a falta de estrutura no que diz respeito à cultura no território, revelando uma realidade dos municípios e comunidades rurais que não dispõe dessas atividades. No geral, as pessoas participam dos festejos religiosos, por ser uma das pouquíssimas atividades culturais dos municípios. O segundo elemento com valor baixo é a situação ambiental $(0,559)$, constatando que o território não avançou de forma significativa com relação à normatização ambiental voltada para a preservação de áreas degradadas, preservação permanente da mata nativa e controle de resíduos sólidos.

Já Caniello (2016) chegou aos seguintes dados nos 37 territórios estudados na sua pesquisa; os três quesitos melhores avaliados referem-se a indicadores da terceira instância, isto é, aos "efeitos do desenvolvimento": (1) "permanência dos membros da família na unidade de produção", com índice médio de 0,7529 e 74\% de avaliações positivas; (2) "estado nutricional da família", com 0,6550 e 60\%; e (3) "mudança na situação econômica da família", com 0,6378 e, também, 60\%. No que tange à primeira instância, "fatores do desenvolvimento", despontam a "condições de moradia", com índice médio de 0,6311. 
Tabela 6. Território Sertão do Apodi: instância Efeitos do Desenvolvimento e indicadores das condições de vida das famílias rurais

\begin{tabular}{cccccc} 
4- DIMENSÃo 3: efeitos do desenvolvimento & $\mathbf{0 , 6 3 8}$ & Freq. & Mínimo & Máximo & $\begin{array}{c}\text { Desvio } \\
\text { Padrão }\end{array}$ \\
17. Condições de alimentação e nutrição & 0,634 & 270 & 0,000 & 1,000 & 0,204 \\
18. Condições de saúde & 0,643 & 270 & 0,000 & 1,000 & 0,233 \\
19. Permanência dos familiares no domicílio & 0,833 & 270 & 0,000 & 1,000 & 0,239 \\
20. Situação econômica & 0,635 & 270 & 0,000 & 1,000 & 0,207 \\
21. Situação ambiental & 0,559 & 270 & 0,000 & 1,000 & 0,206 \\
22. Participação em organizações comunitárias & 0,637 & 270 & 0,000 & 1,000 & 0,261 \\
23. Participação política & 0,675 & 270 & 0,000 & 1,000 & 0,267 \\
24. Participação em atividades culturais & 0,490 & 270 & 0,000 & 1,000 & 0,321 \\
\hline
\end{tabular}
Fonte: Brasil (2012a).

Da mesma forma que no Território Açu-Mossoró, vale destacar que os significados do desenvolvimento extrapolam os aspectos puramente econômicos, e ativos e capitais diversos aliados a fatores não econômicos, como a liberdade e as capacidades individuais, se traduzem em estratégias de reprodução econômica e social. Todavia, apesar de o índice obtido ser o mais alto $(0,638)$, cabe considerar a sua associação com os "Fatores" e com as "Características de desenvolvimento" para a dinamização do território. Graficamente, os subitens desta instância estão representados no Biograma da instância, visto na Figura 9.

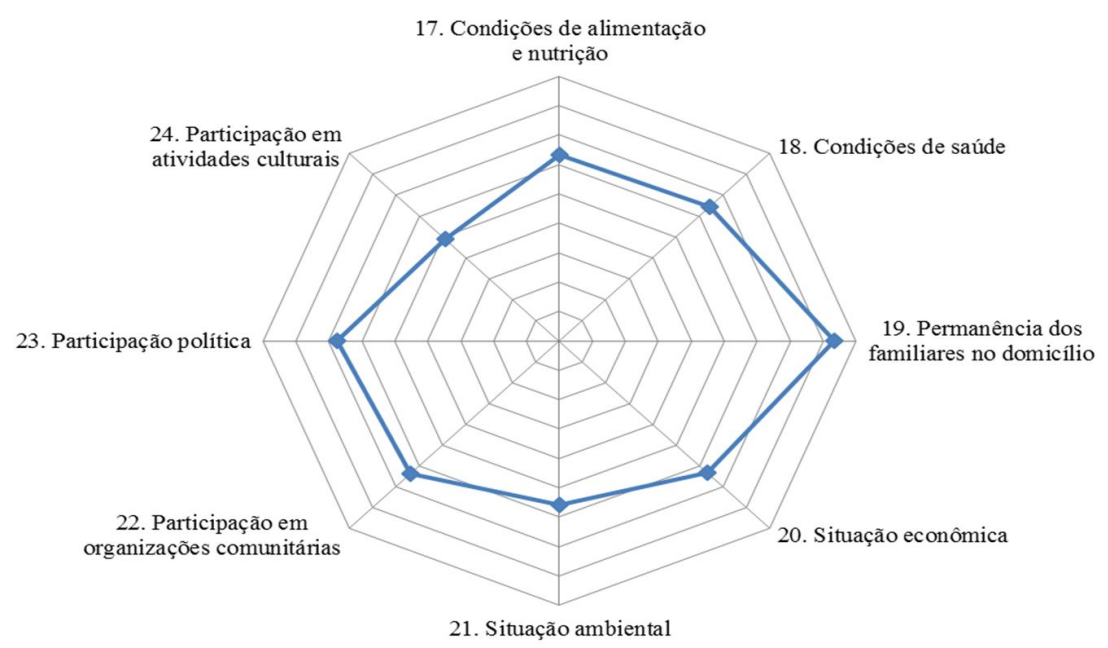

Figura 9. Território Sertão do Apodi: Biograma representativo da instância Efeitos do Desenvolvimento Fonte: Brasil (2012a).

No que diz respeito à dimensão 3, "os efeitos do desenvolvimento", Toigo \& Conterato (2017) apresentam que essa dimensão do ICV refletiu a respeito dos efeitos dos processos de desenvolvimento no Território Zona Sul (RS), a partir da análise dos funcionamentos realizados pelas famílias rurais e de seu conjunto capacitário. Com o maior resultado geral $(0,644)$, "médio alto", dentre as três dimensões apresentadas na pesquisa realizada pelos autores, valores bem próximos aos encontrados no Território Sertão de Apodi com o resultado de $(0,638)$ e no Açu-Mossoró, com $(0,633)$. Todavia, o pior resultado dos indicadores da dimensão 3 nos dois territórios estudados foi participação em atividades culturais, Sertão do Apodi com $(0,490)$ e Açu-Mossoró com $(0,521)$, resultados que corroboram com a pesquisa de Toigo \& Conterato (2017), que percebem que o pior indicador avaliado em termos quantitativos e qualitativos nos dados da dimensão "os efeitos do desenvolvimento" no Território Zona Sul (RS),referia-se às participações em atividades culturais, aspecto relacionado ao capital social. 


\section{Considerações finais}

Baseando-se na análise dos resultados do Índice de Condições de Vida (ICV), buscou-se apontar questionamentos no sentido da validade da sua aplicação para demonstrar que esta metodologia possibilita captar, por meio da percepção dos indivíduos, a diversidade de situações em determinado momento. E essas situações podem ser comparadas com um momento posterior, a partir do qual torna-se possível explicar a complexidade e a diversidade de realidades territoriais de desenvolvimento rural. Diante disso, constatou-se aqui uma busca no sentido de ressaltar significados do desenvolvimento que sugerem como alternativas que enfatizam aspectos além dos meramente econômicos, como a garantia de direitos civis, liberdade, justiça social, sustentabilidade, e outras dimensões da vida humana.

De acordo com o exposto acima, o ICV se revelou um indicador possuidor de uma metodologia que possibilita comparar situações antes e depois, ou seja, de um determinado ponto no tempo ICV poder representar determinada situação (ou um retrato) das condições de vida que pode ser comparada a outra situação (retrato) de um período ou ponto em um tempo depois. Dessa forma, ao fazer comparações das condições de vida de momentos diferentes passa a ser possível também observar sua dinâmica, podendo-se constatar, por exemplo, os impactos das políticas implantadas e das ações desencadeadas por estas na promoção do desenvolvimento rural nos territórios.

Este, inclusive, sempre foi um dos principais objetivos expressos pela SDT/MDA ao demandar um indicador capaz de apontar instâncias e dimensões acerca das condições de vida nos territórios rurais, a partir da percepção de seu público-alvo, os agricultores familiares. Ao analisar o ICV observou-se, como já apontado, que os resultados indicam que não há uma correspondência direta entre fatores, características e efeitos do desenvolvimento. O Quadro 4 mostra uma síntese dessa não correspondência quando comparadas as dimensões das instâncias do ICV dos territórios Açu-Mossoró e Sertão do Apodi que tiveram as médias mais baixas e as que alcançaram as mais altas.

Quadro 4. As três instâncias do ICV dos territórios Açu-Mossoró e Sertão do Apodi e suas dimensões que se destacaram com as médias mais altas e as mais baixas

\begin{tabular}{|c|c|c|c|}
\hline \multicolumn{4}{|c|}{ Fatores do Desenvolvimento } \\
\hline \multicolumn{2}{|c|}{ Açu/Mossoró } & \multicolumn{2}{|c|}{ Sertão do Apodi } \\
\hline Dimensão médias altas & Dimensão médias baixas & Dimensão médias altas & Dimensão médias baixas \\
\hline Condições de moradia & Acesso ao crédito & Escolaridade & Acesso assistência técnica \\
\hline Mão de obra da família & Acesso assistência técnica & Condição de moradia & Acesso ao credito \\
\hline Escolaridade & Acesso aos mercados & $\begin{array}{l}\text { Área utilizada para a } \\
\text { produção }\end{array}$ & Acesso aos mercados \\
\hline \multicolumn{4}{|c|}{ Característica do Desenvolvimento } \\
\hline \multicolumn{2}{|c|}{ Açu/Mossoró } & \multicolumn{2}{|c|}{ Sertão do Apodi } \\
\hline Dimensão médias altas & Dimensão médias baixas & Dimensão média alta & Dimensões médias baixas \\
\hline $\begin{array}{l}\text { Preservação da } \\
\text { vegetação nativa }\end{array}$ & $\begin{array}{l}\text { Diversificação nas fontes de } \\
\text { renda familiar }\end{array}$ & $\begin{array}{l}\text { Conservação da área } \\
\text { de produção }\end{array}$ & $\begin{array}{l}\text { Diversificação das fontes de } \\
\text { renda }\end{array}$ \\
\hline $\begin{array}{l}\text { Conservação da área de } \\
\text { produção: solo }\end{array}$ & $\begin{array}{l}\text { Conservação das fontes de } \\
\text { água }\end{array}$ & Produtividade da terra & Renda Familiar \\
\hline Produção da terra & $\begin{array}{l}\text { Diversificação da produção } \\
\text { agrícola }\end{array}$ & $\begin{array}{l}\text { Conservação das } \\
\text { fontes de água }\end{array}$ & $\begin{array}{c}\text { Diversificação da produção } \\
\text { agrícola }\end{array}$ \\
\hline \multicolumn{4}{|c|}{ Efeitos do Desenvolvimento } \\
\hline \multicolumn{2}{|c|}{ Açu/Mossoró } & \multicolumn{2}{|c|}{ Sertão do Apodi } \\
\hline Dimensão média alta & Dimensão média baixa & Dimensão média alta & Dimensão média baixa \\
\hline $\begin{array}{c}\text { Permanência dos } \\
\text { familiares no domicilio }\end{array}$ & $\begin{array}{l}\text { Participação em atividades } \\
\text { culturais }\end{array}$ & $\begin{array}{l}\text { Permanência dos } \\
\text { Familiares no } \\
\text { domicílio }\end{array}$ & $\begin{array}{l}\text { Participação em atividades } \\
\text { culturais }\end{array}$ \\
\hline
\end{tabular}

Fonte: Brasil (2012a). Elaborado pelos autores. 
Essa não correspondência pode resultar, talvez, da presença de ativos e capitais aliados às liberdades individuais que se apresentam de maneiras diferentes a partir da percepção dos indivíduos, como que os indivíduos se valessem de seus entitulamentos e se aproveitam de estratégias para conseguir realizar certas ações. No entanto, a diversidade social, econômica, ambiental e cultural que caracteriza os territórios Açu-Mossoró e Sertão do Apodi parece reforçar e afirmar as diferentes percepções expressas pelos indivíduos sobre as suas condições de vida. A pesquisa constatou, ainda, a relevância cada vez maior das rendas não agrícolas como estratégias presentes na agricultura familiar dos territórios Açu-Mossoró e Sertão do Apodi, estas sendo, muitas vezes, fruto da diversificação das fontes de renda (serviço público, venda de força de trabalho fora da propriedade etc.) ou de aposentadorias e pensões. Esta representa uma constatação da diversidade e da pluriatividade que caracterizam a agricultura familiar dos territórios Açu-Mossoró e Sertão do Apodi. Embora esta seja uma realidade mais conhecida em regiões mais desenvolvidas, especialmente na região Sul do Brasil, novos estudos sobre essas estratégias da agricultura familiar tornam-se importantes, principalmente no sentido de direcionar políticas públicas de desenvolvimento rural.

Cabe ressaltar que a análise utilizando a metodologia do ICV indica o quanto a necessidade da defesa dos significados de desenvolvimento, na perspectiva de Amartya Sen, em que os indivíduos e suas organizações coletivas, além dos seus valores e percepções constituem o papel central na análise. Isso a partir do caráter multidimensional e com ampla participação dos indivíduos e seus valores e representações, o que se configura um processo promissor, porém complexo. Por isso, constata-se que para abarcar o fenômeno do desenvolvimento territorial rural, uma variedade de atividades pode ser sugerida no sentido de aprofundar as constatações na análise do ICV. Como consta em Rambo et al. (2012) e Nunes et al. (2019), pesquisas fundamentadas em análises objetivas e subjetivas que visam a compreensão de como se formam as representações sociais dos atores locais/territoriais, nas suas mais variadas dimensões; análises das principais instâncias e dimensões que contribuem para a construção destas representações; comparações entre as representações de diferentes grupos do território e fomento a pesquisas capazes de interpretar e explicar a relação entre representações sociais e identidade no território. Estas atividades parecem imprescindíveis para uma maior compreensão das dinâmicas sociais e dos efeitos das políticas públicas no território, especialmente no momento atual, em que a política territorial se encontra estancada em nível da SDT/MDA, devido à ebulição político-institucional que o Brasil atravessa.

Concluindo, os resultados da utilização do ICV demonstram que esta metodologia possibilita captar a diversidade de situações em certo momento as quais podem ser comparadas com um momento depois, a partir do qual torna-se possível interpretar e buscar explicações para a complexidade e diversidade das realidades territoriais. Considera-se, portanto, que diante de uma realidade de retomada da política territorial e dos arranjos institucionais, especialmente os que constituem os Colegiados de Desenvolvimento Territorial, além de outras organizações da sociedade civil, o direcionamento deve ser de afirmação dos significados de desenvolvimento como liberdade de Amartya Sen.

Enfim, frente à afirmação e ao reconhecimento político-institucional da dinâmica territorial, há um consenso de que fatores e características meramente econômicos e técnico-produtivos são meios e não fins do desenvolvimento. E o ICV, por ter destacado por meio da sua metodologia as condições de vida a partir da percepção dos indivíduos, foi capaz de contribuir para uma compreensão mais detalhada de uma das faces mais frágeis da Política Nacional de Desenvolvimento Territorial, através dos indicadores que constituem os fatores, as características e os efeitos do desenvolvimento de territórios rurais de regiões mais pobres.

\section{Referências}

Bastian, L., Schneider, S., Rambo, A. G., Krone, E. E., de Oliveira, C. D., \& Conterato, M. A. (2016). Desenvolvimento e território: o Índice de Condição de Vida (ICV) do território rural Zona Sul do Rio Grande do Sul. Ensaios FEE, 37(3), 643-672. 
Brasil . Ministério do Desenvolvimento Agrário. (2003). Referências para o desenvolvimento territorial sustentável. Brasília: IICA/Condraf/MDA/NEAD.

Brasil. Ministério do Desenvolvimento Agrário. (2004). Referências para o apoio ao desenvolvimento territorial (33 p.). Brasília: MDA/SDT. Recuperado em 30 de janeiro de 2018, de http:// www.facesdobrasil.org.br/.../239-programa-nacional-de-desenvolvimento

Brasil. Ministério do Desenvolvimento Agrário. (2005). Referências para a gestão social de territórios rurais. (Documento Institucional, № 3). Brasília: MDA/SDT.

Brasil - Sistema de Informações Territoriais (SIT). (2010). Plano Territorial de Desenvolvimento Rural Sustentável Açu-Mossoró e Sertão do Apodi: Mossoró. Brasília: SIT

Brasil. Ministério do Desenvolvimento Agrário. (2011). Sistema de Gestão Estratégica: índice de condições de vida. Brasília: MDA. Disponível em: http://sge.mda.gov.br/ind/ind_re/doc/Manual_ICV_11_03_2011.pdf Acesso em: 21 mar. 2017.

Brasil. (2012a). Inovação, Diversidade e Sustentabilidade na Gestão de Territórios Rurais: monitoramento e avaliação do desenvolvimento do Território Sertão do Apodi (RN): relatório final (pp. 48). Brasília: SGE/CAI.

Brasil. (2012b). Inovação, Diversidade e Sustentabilidade na Gestão de Territórios Rurais: monitoramento e avaliação do desenvolvimento do Território Açu-Mossoró (RN): relatório final (pp. 57). Brasília: SGE/CAI.

Brasil. (2016) - Territórios da Cidadania Açu-Mossoró e Sertão do Apodi (RN) (1 mapa, colorido. Escala 1:6000.000) Brasília: NEDET/UERN.

Caniello, M. (2016). Identidade e qualidade de vida nos territórios da cidadania. Sociologias, 3, 300-337.

Casimiro, L. A. O., Vilpoux, O. F., \& Nogueira, M. A. F. S. (2015). Índice de Condição de Vida (ICV) no Território da Cidadania da Reforma. In Anais do $2^{\circ}$ Seminário Internacional de Integração $e$ Desenvolvimento Regional - ECAECO. Ponta Porã: Editora UFMS.

Echeverri, R. (2010). Emergência e evolução do Programa de Desenvolvimento Sustentável dos Territórios Rurais e nos Territórios da Cidadania. In A. Favareto (Eds.), Políticas de Desenvolvimento Territorial Rural no Brasil: avanços e desafios (Série Desenvolvimento Rural Sustentável, pp. 81-114). Brasília: IICA.

Kageyama, Â. A. (2008). Desenvolvimento rural: conceitos e aplicação ao caso brasileiro. Porto Alegre: Editora da UFRGS.

Leite, S. P., \& Wesz Júnior, V. J. (2012). Um estudo sobre o financiamento da política de desenvolvimento territorial no meio rural brasileiro. Revista de Economia e Sociologia Rural (Impresso), 50(4), 645-666.

Nunes, E. M., Gondim, M. F. R., \& Silva, M. R. F. (2019). Identidade e reestruturação produtiva nos territórios Açu-Mossoró e Sertão do Apodi, no Rio Grande do Norte. Estudos Sociedade e Agricultura 27, 137-166.

Nunes, E. M., Gondim, M. F. R., Godeiro, K. F., Oliveira, I. A., \& Gois, B. V. (2014). O Índice de Capacidades Institucionais $(\mathrm{ICl})$ como mecanismo da gestão social e da governança nos territórios rurais. Planejamento e Políticas Públicas, 42, 301-330.

Nunes, E. M., Tôrres, F. L., Silva, M. R. F., Sa, V. C., \& Godeiro-Nunes, K. F. (2015). Dinamização Econômica e Agricultura Familiar: limites e desafios do apoio a Projetos de Infraestrutura (PROINF) em territórios rurais do Nordeste. Revista de Economia e Sociologia Rural, 53, 529-554.

Perico, R. E. (2009). Identidade e território no Brasil. Brasília: Instituto Interamericano de Cooperação para a Agricultura.

Rambo, A.G., Bastian, L., Conterato, M. A., Casaril J., Del Ré, M. F., Gomes, C. A., Radünz, A. F. O., \& Schneider S. (2015). O Índice de Condições de Vida (ICV): construindo metodologias de análise e avaliação de dinâmicas territoriais do desenvolvimento rural. Revista em Gestão, Inovação e Sustentabilidade, 1(1), 68-94.

Rambo, A. G., Conterato, M., Schneider, S., Re, M. F., \& Gomes, C. A. (2012). Território e Desenvolvimento na Escala Humana: condições de vida e gestão territorial no Sul do Rio Grande do Sul. In Anais do $50^{\circ}$ Congresso da Sociedade Brasileira de Economia Administração e Sociologia Rural. Vitória: SOBER.

Sen, A. K. (2000). Desenvolvimento como liberdade. São Paulo: Companhia das Letras.

Sen, A. (2010). A ideia de justiça. Tradução: Nuno Castello-Branco Bastos. Coimbra: Almedina.

Sepúlveda, S. (2005). Desenvolvimento microrregional sustentável: métodos para planejamento local. Brasília: IICA. 
Toigo, C. H., \& Conterato, M. A. (2017). Pobreza, vulnerabilidade e desenvolvimento no território rural zona sul: o que aponta o Índice de Condição de Vida? Revista de Economia e Sociologia Rural, 55(2), 267-284.

van der Ploeg, J. D. (2008). The new pensantries: struggles for autonomy and sustainability in an era of empire and globalization. Sterling: Earthscan Publisher.

Waquil, P. D., Rambo, A., Conterato, M. A., Schneider, S. (2007). Proposição do Índice de Condições de Vida (Relatório de pesquisa). Porto Alegre: PGDR/UFRGS, SDT/MDA.

Wesz Júnior, V. J., \& Leite, S. P. (2010). Financiamento da política de financiamento territorial: relatório final (78 p). Brasília: IICA/OPPA. Recuperado em 18 de março 2016, de

http://www.concope.gob.ec/redif/action/file/download?file_guid=1425

Data de submissão: 30 de janeiro de 2018.

Data de aceite: 28 de outubro de 2018.

Classificação JEL: I3, O1, Q1, R1. 